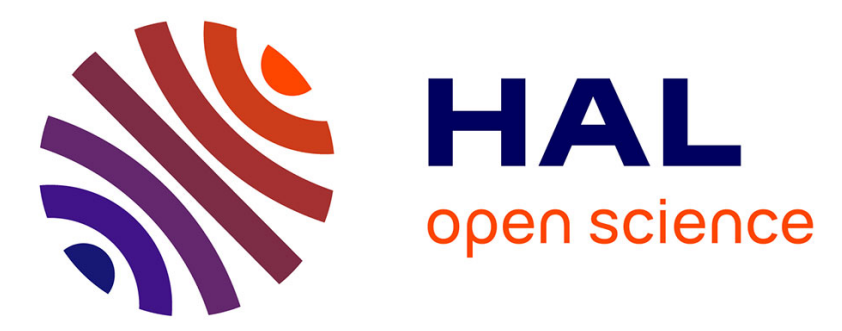

\title{
La question des premières installations rurales italiennes en Gaule transalpine (fin du IIe s.-milieu du Ier s. avant J.-C.)
}

Stéphane Mauné

\section{- To cite this version:}

Stéphane Mauné. La question des premières installations rurales italiennes en Gaule transalpine (fin du IIe s.-milieu du Ier s. avant J.-C.). Gallia - Archéologie de la France antique, 2000, 57, pp.231-260. 10.3406/galia.2000.3021 . hal-01902020

\section{HAL Id: hal-01902020 \\ https://hal.science/hal-01902020}

Submitted on 16 Jan 2020

HAL is a multi-disciplinary open access archive for the deposit and dissemination of scientific research documents, whether they are published or not. The documents may come from teaching and research institutions in France or abroad, or from public or private research centers.
L'archive ouverte pluridisciplinaire HAL, est destinée au dépôt et à la diffusion de documents scientifiques de niveau recherche, publiés ou non, émanant des établissements d'enseignement et de recherche français ou étrangers, des laboratoires publics ou privés.

\section{(1) (1) $\$$}

Distributed under a Creative Commons Attribution - NonCommercial - NoDerivatives 44.0 


\title{
LA QUESTION DES PREMIÈRES
}

INSTALLATIONS RURALES ITALIENNES

EN GAULE TRANSALPINE

(FIN DU II ${ }^{\mathrm{e}}$ S.-MILIEU DU I ${ }^{\mathrm{er}}$ S. AVANT J.-C.)

\author{
Stéphane MAUNÉ*
}

Mots-clés. Gaule transalpine, occupation du sol, établissement rural, mines, centuriations, Italiens, romanisation, Cicéron.

Key-words. Transalpine Gaul, land occupalion, rural settlemenl, mines, centuriations, Ilalians, romanization, Ciceron.

Résumé. Si les historiens s'accordent, presque unanimement, à placer la conquête de la Gaule transalpine dans les années 121 -118 avant J.-C., on reste bien mal renseigné sur les formes et les expressions de la domination italienne dans cette nouvelle province, et ce jusque vers le troisième quart du $I^{\text {er }}$ s. avanl J.-C. Quelques points forts (construction de la via Domitia, fondation de Narbonne, de Forum Domitii...) éclairent cependant les premiers efforts de Rome pour structurer ce territoire, mais la question des premières installations italiennes dans cette zone reste largement ouverte, notamment en milieu rural.

À la lumière des études d'occupation du sol les plus récentes, et en confronlanl les données littéraires, épigraphiques et économiques disponibles, l'auteur met en évidence des différences régionales assez marquées qui indiquent que l'immigration italienne antérieure au milieu du Irr s. avant J.-C. semble surtoul concentrée dans une zone située entre le fleuve Hérault et les Pyrénées. Ce phénomène trouve vraisemblablement son origine dans la proximité de la colonie et du port de Narbonne, mais peut-être aussi de celle de l'Espagne toute proche et touche aussi bien les plaines et les coteaux (activités agricoles) que les zones de montagne (activités minières).

Abstract. If historians do agree, almost unanimously, thal the conquest of Transalpine Gaul dates from the years 121-118 BC, we do not have much information on the forms and expressions of Italian domination in the new province until the third quarter of the $1^{\text {st }}$ century BC. A few strong facts (construction of the via Domitia, foundation of Narbonne and of Forum Domitii...) however throw light on the first attempts of Rome to organize this territory, yel the question of the earliest Italian settlements in this area is still wide open, particularly in rural context.

Under the light of the most recent land-occupation studies, making every possible use of available literary, epigraphic and economic sources, the author underlines rather clear regional differences. The Italian immigration before the mid-1. ${ }^{\text {st }}$ century BC seems to have been mostly concentrated between the river Hérault and the Pyrenees. This phenomenon could have its roots in the vicinity of the Narbonne colony and harbour, but also perhaps in the proximity of Spain. It concerns plain and uplands (agriculture) as well as mountains (mining activities).

L'essor récent de l'archéologie spatiale dans le sud de la France, dont rend bien compte la multiplication des études d'occupation du sol, et les échanges de plus en plus nombreux entre historiens et archéologues permettent aujourd'hui de proposer quelques pistes de recherches concernant la problématique des débuts de la

* UMR 154 du CNRS, 390 avenue de Pérols, F-34970 Lattes. 
présence romaine en Gaule transalpine ${ }^{1}$. L'étude qui est présentée ici s'appuie sur une confrontation de l'ensemble des données disponibles: on tentera de préciser et d'analyser à quel moment et de quelle(s) manière(s) se sont mises en place les premières installations rurales italiennes dans la province de Gaule transalpine. Le croisement de plusieurs sources d'informations autorise en effet une nouvelle approche de ce phénomène qui conditionne la romanisation et l'adhésion précoce de cette partie de la Provincia au modèle romain. Il serait en effet surprenant que la romanisation de la Gaule méridionale se soit faite seulement à partir des centres urbains comme Narbonne, Béziers, Nîmes et les cités de la vallée du Rhône. Bien d'autres éléments doivent être pris en compte (Feugère et al., 1998) et il faut aussi insister davantage sur l'élément déterminant que constitue la présence précoce - et qui sera de plus en plus importante après les années 50-40 avant J.-C. avec les déductions coloniales - d'Italiens dans les campagnes. C'est notamment par ce biais que les techniques, les innovations, les habitudes culturelles et les modes d'exploitation et d'organisation ont pu réellement et rapidement imprégner le monde indigène.

Conquise entre les années 121 et 118 avant J.-C., la Gaule transalpine apparaît comme une province particulièrement mal connue du point de vue de son histoire institutionnelle, du moins durant les premières décennies de son existence (Goudineau, 1978, 1996, p. 9-15; Hermon, 1993; Soricelli, 1995). Il faut sans doute expliquer cette situation par l'indigence des sources épigraphiques tardo-républicaines, mais l'on peut également faire remarquer que les auteurs antiques ont été peu prolixes à son sujet.

1. Voir notamment F. Favory, J.-I. Fiches (dir.), 1994 ; la publication récente (1998) du projet collectif «Archéomedes » et les actes des deux colloques tenus à Béziers en 1994 et 1997. Cette question est au centre des préoccupations d'un groupe d'archéologues et d'historiens: I. Bermond, M.-L. Bonsangue, L. Carozza, C.-A. de Chazelles, M. Christol, M. Clavel-Lévêque, E. Dellong, M. Feugère, J. Kotarba, S. Mauné (coord.), C. Moatti, M. Passelac, C. Pellecuer, G. Rancoule, C. Sanchez, réunis au sein d'un projet collectif de recherche: "Dynamique et formes de l'occupation du sol en Transalpine occidentale aux II ${ }^{e}$ et ${ }^{\text {rr }} s$. avant J.-C. ", agréé et financé par le ministère de la Culture en février 1999. L'un des premiers objectifs de ce collectif est de rassembler et de publier l'ensemble de la documentation matérielle disponible (sites, ensembles céramiques et autres, inventaires détaillés), pour proposer ensuite une réflexion globale et croisée sur ce thème de recherche.
Bien des incertitudes demeurent - et nous aurons l'occasion d'y revenir - en sorte que la question de la présence italienne dans la province reste un sujet difficile. C'est que la diversité et le caractère peut-être tout à fait commun, pour les contemporains, d'une immigration italienne précoce n'ont guère contribué à ce que les sources anciennes y fassent référence de manière explicite.

On doit néanmoins rappeler ici les indications rapportées par Cicéron, qui, dans deux de ses plaidoyers, le Pro Quinctio et le Pro Fonteio ${ }^{2}$, évoque, comme allant de soi, la présence d'Italiens installés dans les campagnes de la province dans les années 80 et 70 avant J.-C. Ces informations, que nous évoquerons au fur et à mesure de l'exposé, sont très précieuses et, à la lecture de ces deux textes, on a bien l'impression que Cicéron décrit des situations finalement très banales: voyages terrestres entre la péninsule et la province, existence de sociétés italiennes exploitant les ressources agricoles, pratiquant l'élevage, et se livrant au commerce des esclaves malgré les événements politiques et militaires qui agitent les premières décennies de l'occupation romaine. Quinctius réside même en Gaule, dans l'une de ses propriétés, durant plus d'une année.

Cette présence italienne en Gaule transalpine - hors du secteur de Narbonne qui a accueilli une déduction coloniale en 118 avant J.-C. (Gayraud, 1981) - peut-elle être mise en évidence par les recherches récentes? Poser cette question revient en fin de compte à s'interroger, d'abord et d'une manière aussi large que possible, sur l'occupation du sol aux Ire et $\mathrm{I}^{\text {er }} \mathrm{s}$. avant J.-C., car on peut saisir ainsi la dynamique des phénomènes de colonisation rurale puis mesurer ou pas, grâce au croisement des données matérielles disponibles, l'importance de l'immigration latine dans les campagnes.

La mise en place et le développement, dans la partie côtière et le long des principales vallées fluviales de l'ancienne province de Transalpine, de programmes de prospection-inventaire ainsi que la réalisation de cartes archéologiques de plus en plus précises permettent en effet de proposer un premier bilan de l'occupation du

2. Cicéron, Discours, I, Pour P. Quinctius, Pour Sex. Roscius d'Amérie, Pour Q. Roscius le comédien, texte établi et traduit par $\mathrm{H}$. de la Ville de Mirmont, J. Humbert, 4* tirage, Paris, Les Belles I.ettres, 1973. Cicéron, Discours, VII, Pour M. Fonteius, Pour A. Cécina, Sur les pouvoirs de Pompée, texte établi et traduit par A. Boulanger, $4^{e}$ tirage, Paris, Les Belles Lettres, 1973. 


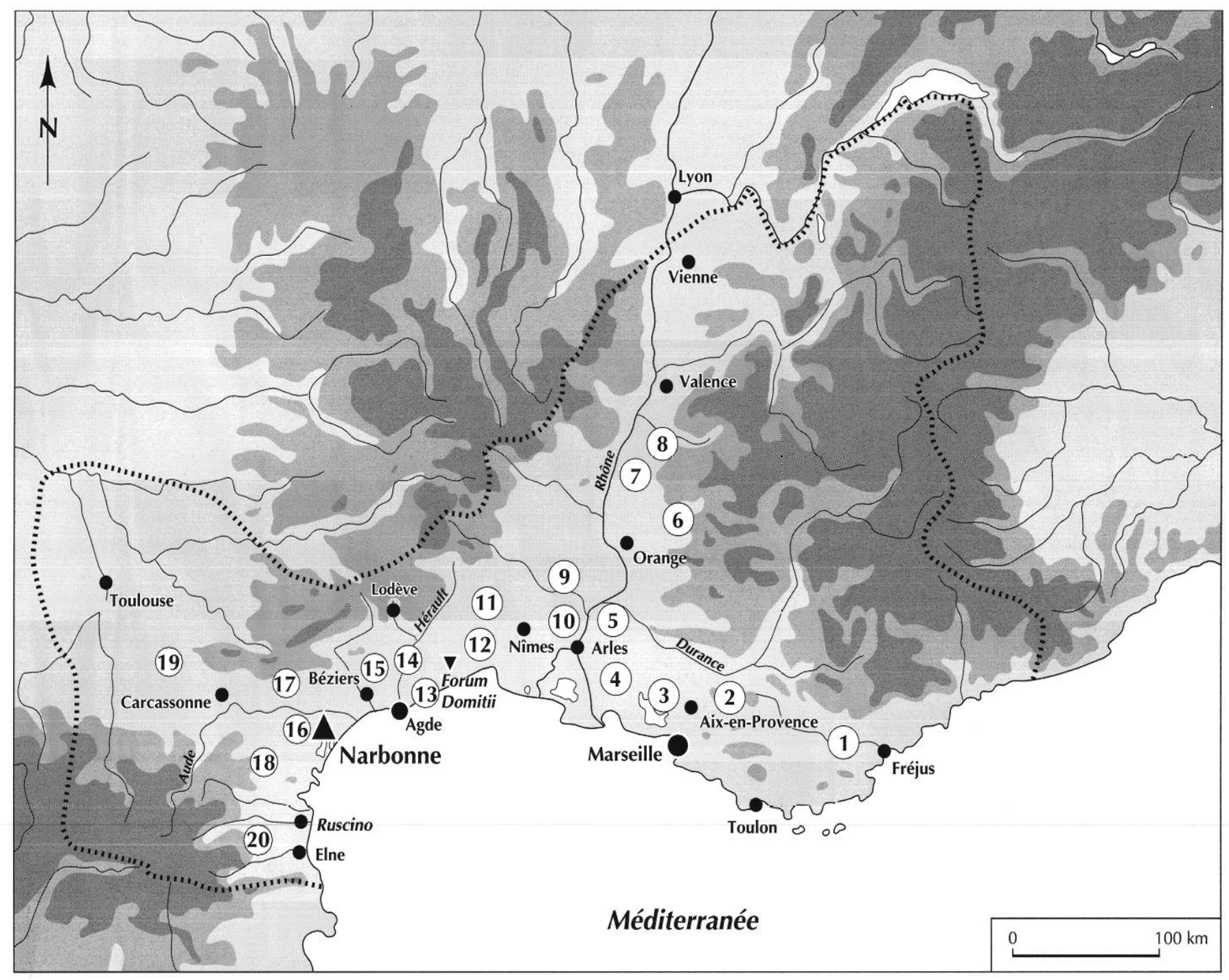

Fig. 1 - Carte de localisation des agglomérations antiques et des microrégions citées dans le texte : 1, vallée de l'Argens (Var); 2, massif de la Sainte-Victoire (Bouches-du-Rhône); 3, étang de Berre (Bouches-du-Rhône) ; 4, plaine de la Crau (Bouches-du-Rhône) ; 5, Alpilles (Bouches-duRhône) ; 6, Haut-Comtat (Vaucluse) ; 7, Tricastin (Drôme) ; 8, Valdaine (Drôme) ; 9, Uzège (Gard) ; 10, Beaucairois (Gard) ; 11, Vaunage (Gard) ; 12, Lunellois (Hérault) ; 13, bassin de Thau et Agadès (Hérault) ; 14, moyenne vallée de l'Hérault (Hérault) ; 15, Biterrois (Hérault) ; 16, Narbonnais (Aude);17, Minervois (Aude) ; 18, Corbières (Aude);19, Lauragais (Aude) ; 20, Roussillon (Pyrénées-Orientales).

sol entre l'époque antérieure à la conquête et la période césaro-triumvirale (fig. 1). La prise en compte des données antérieures à la fin du $\mathrm{II}^{\mathrm{e}}$ s. répond à la nécessité d'inscrire cette recherche dans la longue durée, sans tenir compte, à priori, des césures historiques traditionnelles pour expliquer tel ou tel phénomène mis en évidence par l'archéologie et autorise une lecture plus fine de la situation au I ${ }^{\text {er }}$ s. avant J.-C. Ainsi, si l'on doit encore affiner les distinctions microrégionales, on peut à présent réfuter avec quelques arguments l'hypothèse traditionnelle selon laquelle la dispersion et la descente de l'habitat en plaine seraient des signes de la romanisation des campagnes. Comme dans plusieurs régions de Gaule Chevelue, des établissements ruraux indigènes existaient avant 118 avant J.-C. et il semble que la multiplication de ces sites à partir de la fin du $\mathrm{II}^{\mathrm{e}} \mathrm{s}$. et du début $\mathrm{du} \mathrm{I}^{\mathrm{er}}$ s. avant J.-C. relève d'abord d'un mouvement endogène. Ce phénomène a été mis en évidence, dès les années 1970, par G. Rancoule dans le couloir audois et s'étend maintenant à tout le Languedoc occidental. Dans 
l'Aude, il a été interprété comme l'expression d'un accroissement démographique associé à un apport limité de populations indigènes extra-régionales en provenance d'Aquitaine, du Massif central et des Pyrénées (Rancoule, Schwaller, 1994, p. 232). Néanmoins, comme y invitent les textes de Cicéron déjà cités, demeure la nécessité de s'interroger sur la possibilité et les modalités d'une pénétration lente mais régulière de groupes italiens dans la province à date haute, c'est-à-dire antérieurement aux années 50-30 avant J.-C. qui correspondent au pic des déductions coloniales provinciales. Le croisement des textes, de l'épigraphie et des données relatives aux centuriations peut singulièrement éclairer ces premiers résultats que nous présenterons selon le découpage territorial suivant: Provence et Sud-Est, Languedoc oriental et couloir rhodanien, puis Languedoc occidental et Roussillon. On verra à la lecture de cette première analyse que les situations paraissent contrastées, selon que l'on se place à l'est ou à l'ouest de la zone vallée de l'Hérault/étang de Thau.

\section{LA TRANSALPINE ORIENTALE (PROVENCE, VALLÉE DU RHÔNE ET LANGUEDOC ORIENTAL)}

\section{EN PROVENCE : LE POIDS DU MONDE INDIGÈNE}

En Provence, plusieurs enquêtes microrégionales exhaustives permettent d'aborder la question de l'occupation du sol au II ${ }^{\mathrm{c}} \mathrm{s}$. et dans la première moitié du I $\mathrm{I}^{\mathrm{er}} \mathrm{s}$. avant J.-C. Ainsi, dans les Bouches-du-Rhône, les prospections systématiques effectuées dans le massif de la Sainte-Victoire ont révélé l'existence de vingt-six sites dont la chronologie s'établit à partir du $\mathrm{II}^{\mathrm{e}}$ s. avant J.-C., sans précision, et que l'on a proposé d'interpréter comme des installations saisonnières liées à la conquête des basses terres réalisée à partir des habitats groupés (Jorda, Mocci, 1997, p. 223 et 227). Durant la seconde moitié du I ${ }^{\text {er }}$ s. avant J.-C., la multiplication des établissements ruraux est mise en parallèle avec l'abandon des oppida locaux et cette dispersion apparaît comme une conséquence directe du mode d'exploitation antique. L'hypothèse qui s'impose est celle d'un peuplement indigène dynamisé par son propre accroissement démographique (D'Anna et al., 1992, p. 291-293). Un peu plus au sud, les recherches conduites par F.' 'I'rément autour de l'étang de Berre (Bouches-du-Rhône) ont montré un essor réel de l'habitat de plaine à partir du $\mathrm{II}^{\mathrm{c}} \mathrm{s}$. avant J.-C., mais l'auteur n'évoque pas la question d'un apport de population exogène durant le $\mathrm{I}^{\mathrm{er}} \mathrm{s}$. avant $\mathrm{J}$.-C. et constate seulement que la densité maximale du peuplement rural est atteinte au siècle suivant (Trément, 1996, p. 104-105). Dans la basse vallée de l'Arc (Bouches-duRhône), F. Verdin observe qu'à la fin de l'âge du Fer, la plaine et les piémonts se couvrent d'un réseau d'habitats dispersés. Cependant, la rareté du mobilier, bien souvent noyé ultérieurement parmi des lots plus importants de matériel, et son mauvais état de conservation gênent leur datation: " en l'absence de fouille, la fondation de ces établissements peut tout aussi bien être rapprochée de la fin du $\mathrm{II}^{\mathrm{e}}$ s. que de celle du I ${ }^{\text {er }}$ s. av. J.-C. » (Verdin, 1996, p. 119). Plus récemment, et à propos de la région située autour de Marseille, elle postule que l'apparition et la multiplication des établissements de plaine ou de versants - " facilement repérables en prospection par l'abondant mobilier bien daté qu'ils recèlent » - sont la conséquence directe de la conquête romaine (Verdin, 1999, p. 60). On passerait ainsi, en l'espace d'une génération, d'un système d'occupation du sol totalement dominé par les "établissements fortifiés de hauteur » à une situation beaucoup plus hétérogène, marquée par la complexité et l'hétérogénéité du réseau d'habitat, traduisant « la mise en valeur de nouvelles terres » par les communautés indigènes. Cependant, le fait que cette région soit très urbanisée et que paradoxalement les fouilles préventives y aient été très peu nombreuses invitent à reconsidérer, sous un angle critique, l'absence de site antérieur à la conquête romaine; l'auteur écrit d'ailleurs, au sujet de la plaine du bassin d'Aix-enProvence « qu'elle reste définitivement hors d'atteinte pour l'archéologie à cause d'une urbanisation tentaculaire due au développement des industries bordant l'étang " (de Berre) et l'exemple de Nîmes et de ses campagnes - où les fouilles préventives ont démontré l'existence de sites de plaine antérieurs à la conquête romaine (Sauvage, 1996, p. 151) - est peut-être à prendre en considération. Pour les Alpilles et la Montagnette, la situation paraît plus nuancée puisque, tout en constatant une très nette multiplication des points d'occupation isolés de plaine à partir du milieu du ${ }^{\text {er }}$ s. avant J-C., P. Arcelin observe également l'existence d'établissements ruraux en plein $\mathrm{II}^{\mathrm{e}} \mathrm{s}$. Selon lui, il semble bien que désormais l'occupation des territoires d'exploitation s'orga- 
nise autour de regroupements plus modestes qu'auparavant, de type hameau ou ferme (Arcelin, 1999, p. 70).

Plus à l'est, dans la vallée de l'Argens (Var), l'enquête archéologique a mis en évidence l'existence d'un réseau très dense d'établissements ruraux et/ou de hameaux qui apparait au début du I ${ }^{\text {er }}$ s. avant J.-C. : autour de la ferme de Tout-Egau, sept sites ont ainsi été reconnus sur une zone inférieure à $8 \mathrm{~km}^{2}$ (Bérato, 1994, p. 3). Autour de la villa des Mesclans à La Crau, la carte d'occupation du sol, dressée par J.-P. Couderc et M. Pasqualini, fait apparaître que la dispersion de l'habitat n'est sensible que dans la seconde moitié du I ${ }^{\text {er }}$ s. avant J.-C. et peut éventuellement être mise en relation avec la cadastration de la plaine, qui interviendrait donc à la même époque (Borréani, Brun, 1998, p. 201-203 et fig. 1). Toutefois, J. Bérato, M. Borréani, C. Gébara et J.-M. Michel estiment que la création de la voie reliant les Alpes-Maritimes à Aquae Sextiae et la fondation de Forum Voconi, dans la première moitié du $\mathrm{I}^{\mathrm{er}} \mathrm{s}$. avant $\mathrm{J}$.-C., ont pu favoriser la venue d'Italiens à date haute (Bérato et al., 1995, p. 73).

Enfin, les prospections systématiques menées dans la plaine de la Crau (Bouches-du-Rhône) depuis le début des années 1990 ont entraîné la découverte de plus d'une centaine de bergeries du Haut-Empire dont six ont pu être fouillées (Badan et al., 1995). D'autres sites (villae, habitats groupés...) ont également été inventoriés et soulignent l'importance de l'occupation de cette plaine, pourtant réputée improductive durant l'Antiquité. Récemment, une fouille réalisée au lieu-dit La Brune a permis la mise au jour d'un bâtiment à cour centrale d'environ $850 \mathrm{~m}^{2}$, interprété comme une auberge implantée en bordure d'une voie antique (Badan et al., 1997). La chronologie de cette installation est très intéressante puisque l'analyse du mobilier céramique et des monnaies recueillies sur place indique qu'elle a été détruite vers le milieu du $\mathrm{I}^{\text {er }} \mathrm{s}$. avant J.-C. peut-être, comme le suggère la trouvaille d'un trait de catapulte et d'ossements humains découverts dans la couche de destruction, lors d'un épisode militaire.

Cette découverte, passionnante à plus d'un titre, pose la question de la datation effective de l'apparition d'une partie des bergeries répertoriées dans cette microrégion : il est possible que certaines d'entre elles remontent en fait à la première moitié du I ${ }^{\mathrm{er}} \mathrm{s}$. avant J.-C. : les bâtiments Négreiron-Négrès 4 et 12, le groupe du mas Blanc, de l'Oule et de Figuière ont par exemple livré du numéraire de cette époque (Badan et al., 1995, p. 298, tabl. 6).
O. Badan, J.P. Brun et G. Congès mettent cependant en parallèle l'apparition de l'élevage intensif dans la Crau avec la déduction coloniale des vétérans de la $\mathrm{VI}^{\mathrm{e}}$ légion à Arles en 46 avant J.-C. En effet, outre la possibilité que le mobilier le plus ancien trouvé sur les sites puisse être contemporain de cette fondation, les auteurs font remarquer qu'une partie des vétérans de la $\mathrm{V}^{\mathrm{e}}$ légion était originaire de l'Italie du sud, région de la péninsule où la transhumance est le plus clairement et anciennement attestée par les sources écrites et épigraphiques (Badan et al., 1995, p. 301 ; Brun, 1996b, p. 37).

Pourtant, dans son plaidoyer pour Publius Quinctius en 81 avant J.-C., Cicéron témoigne de l'existence de grands propriétaires de troupeaux et de terres en Gaule transalpine; comme Quinctius, ces derniers pouvaient d'ailleurs diriger de véritables sociétés d'affaires ${ }^{3}$. G. Barruol a proposé de situer l'épicentre de la société de Quinctius et de Naevius dans la moyenne vallée de la Durance, chez les Sebaginniens (Pro Quinctio, XXV, 80 ; Barruol, 1969, p. 291-293). De même, en 69 avant J.-C., lors du procès de Fonteius, Cicéron signale la présence, à côté des trafiquants, des colons, des publicains et des agriculteurs, d'éleveurs et/ou de propriétaires de troupeaux $(\mathrm{V}, 12)$, après avoir précisé que la Gaule est remplie de trafiquants et de citoyens romains $(\mathrm{V}, 11)$. On peut donc se demander à juste titre si les bergeries les plus anciennes de la Crau ne pourraient pas être contemporaines de ces deux procès, d'autant plus que Cicéron, dans son plaidoyer pour Fontéius, distingue bien, dans la liste des partisans du propréteur, la colonie de Narbonne et les citoyens romains installés, ailleurs, dans la Province: agriculteurs, propriétaires et/ou éleveurs de troupeaux et négociants (XX, 46).

\section{LE RÉSULTAT DES FOUILLES}

Des fouilles menées sur des établissements ruraux ont également montré la réalité de l'habitat de plaine de la première moitié, du milieu et du troisième quart du $\mathrm{I}^{\mathrm{er}} \mathrm{s}$. avant J.-C. Ainsi, toujours dans le Var, les travaux de J.-P. Brun et des membres du Centre archéologique ont permis d'établir que certaines fermes/hameaux présentaient un état ancien, mais celui-ci est mis en relation avec une présence indigène, sur la foi des observations

3. Sur les relations entre les gens d'affaires et la propriété foncière, on se reportera à J. Andreau, 1987, p. 370 sqq. 
architecturales et du faciès céramique : L'Ormeau A et B, Tout-Egau à Taradeau (Brun et al., 1993), établissement des Platanes à Saint-Tropez (Brun, 1996a) notamment. Pour la ferme de Costebelle située à proximité de l'agglomération grecque d'Olbia, M. Borréani et J.-P. Brun avancent cependant l'hypothèse, en se fondant notamment sur l'existence probable d'une pastas et d'un foyer creux, que cette exploitation rurale aurait été construite et occupée par des Grecs (Borréani, Brun, 1990, p. 130). De son côté, J. Bérato évoque, au sujet du site Les Laurons/Saint-Pierre aux Arcs-sur-Argens, une présence indigène du milieu du $\mathrm{I}^{\mathrm{er}} \mathrm{s}$. avant J.-C., à laquelle aurait succédé l'installation d'un vétéran de la VIII légion, dans le cadre de la déduction de la colonie de Fréjus ${ }^{4}$ (Bérato, 1996a, p. 3 et 1996b). De même, au Grand-Loou, à La Roquebrussanne, les vestiges mis au jour évoquent, selon les fouilleurs, des baraquements en matériaux périssables à mettre en relation avec la présence " d'individus romanisés " (Brun et al., 1985, p. 236-237). Ces quelques exemples doivent être rattachés à un phénomène mis en évidence par J.-P. Brun qui a observé que « toutes les villae importantes du HautEmpire dans le Var tiraient leur origine d'un établissement parfois modeste, fondé dès le milieu du I ${ }^{\mathrm{er}} \mathrm{s}$. avant J.-C. ». Cette vague de fondations d'habitats nouveaux en des lieux rarement occupés auparavant (plaines, bassins, pieds de colline) correspondrait chronologiquement aux bouleversements sociaux et fonciers liés aux guerres civiles et aux déductions des colonies de vétérans, notamment celle d'Arles (Brun, 1996b, cf. aussi Brun, 1989).

Plus à l'ouest, dans les Bouches-du-Rhône, les vestiges attribuables à la période républicaine sont très peu nombreux. Ainsi, à Eyguières sur le site de Saint-Pierre de Vence 1, sous les niveaux du Haut-Empire, un fossé a livré des amphores italiques, de la céramique non tournée, de la céramique tournée de Marseille et de la campanienne que les fouilleurs placent dans la phase chronologique 120-50 avant J.-C. (Pelletier, Poguet, 1994). Pour P. Arcelin, il pourrait bien s'agir des vestiges très dégradés d'une ferme avec bâtiments sur poteaux porteurs et enclos fossoyés (Arcelin, 1999, p. 70). Dans cette microrégion, seule cette villa, et peut-être l'établissement rural de Romanière auraient été occupés durant la première

4. L'auteur appuie son hypothèse sur la découverte d'une parure d'équipement militaire, mais cet élément pourrait également appartenir à un auxiliaire indigène. moitié du ${ }^{\text {er }}$ s. avant J.-C., les autres sites, une bonne vingtaine, apparaissant durant la seconde moitié de ce siècle (Pelletier, Poguet, 1993, p. 205, tabl. 2).

L'examen des données récentes collectées par les prospections et les fouilles, en Provence et dans le SudEst, fait donc apparaître une vague de créations d'établissements ruraux vers le milieu du Ir $\mathrm{I}^{\mathrm{er}}$. avant J.-C. Pour la période antérieure, on évoque volontiers l'existence de hameaux et d'habitats ruraux indigènes pouvant côtoyer, sur quelques secteurs particuliers correspondant aux territoires des agglomérations grecques (Olbia en particulier), des installations occupées par des populations originaires de ces dernières. La création de la colonie d'Arles en 46 avant J.-C. est mise en relation directe avec cette multiplication des sites ruraux que la fondation de Fréjus (Forum Julii) viendra renforcer une vingtaine d'années plus tard (Cameron, Gébara, 1994, et en dernier lieu, Fiches dir., 1995, p. 230-231). Dans l'ouest varois, la carte archéologique rend également compte de la multiplication des établissements ruraux entre le $\mathrm{I}^{\mathrm{er}} \mathrm{s}$. avant $\mathrm{J}$.C. et le $\mathrm{I}^{\mathrm{er}} \mathrm{s}$. après J.-C. (Delattre et al., 1994, fig. 4). En définitive, l'hypothèse même d'une présence italienne dans les campagnes avant le milieu du I ${ }^{\text {er }} \mathbf{s}$. avant J.-C. n'est pratiquement jamais proposée par les chercheurs travaillant sur cette région de la Province pour expliquer, en partie, la multiplication des sites ruraux après la conquête (voir cependant: Brun, 1999, p. 129 et 151). En revanche, le lien entre les déductions coloniales opérées entre la période césarienne et le début du Haut-Empire et l'apparition d'établissements ruraux à cette époque est clairement affirmé. Il y aurait donc eu des Italiens en Provence, mais seulement après le milieu du $I^{\text {er }} s$. avant J.-C. On peut toutefois s'interroger sur la validité de ce modèle dans la mesure où il existe encore bien des incertitudes sur la chronologie d'apparition de ccs sitcs; surtout si l'on tient compte de la tendance actuelle qui est de faire remonter la date de disparition des amphores Dressel la et de la céramique campanienne $\mathrm{A}$ aux années 50 avant J.-C. (voir infra). De manière plus ponctuelle, on doit aussi rappeler l'existence, au Fugeret, dans les Alpes-deHaute-Provence, du plus ancien mausolée de Gaule dont A. Roth Congès situe la construction dans le deuxième quart du Ir s. avant J.-C. (Roth Congès, 1993, p. 392 ; Bérard, Roth Congès, 1997, p. 209). Bâti à $1300 \mathrm{~m}$ d'altitude, cet édifice funéraire comportant un décor monumental exceptionnel serait celui d'un chevalier 
romain dont on suppose qu'il avait à ferme l'exploitation des mines de métaux précieux de la région. Cependant, l'hypothèse de l'existence de mines tardo-républicaines repose essentiellement sur l'existence de toponymes tels que l'Aurent (or) et Argenton (argent) et si les prospections réalisées dans cette zone isolée au relief très difficile, afin de rechercher les traces éventuelles d'une exploitation minière, n'ont pas encore abouti, des indices sérieux auraient été récemment découverts dans une vallée voisine (rens. A. Roth Congès). Quoi qu'il en soit, l'existence même de ce mausolée témoigne peutêtre d'une réalité antique beaucoup plus complexe qu'il n'y paraît et pose la question de la validité et de la représentativité de nos sources documentaires, loin d'être exhaustives.

En définitive, hormis à Aquae Sextiae/Aix-en-Provence, point d'appui militaire installé au pied d'Entremont, dans la vallée d'Argenton/Le Fugeret et peut-être dans l'actuel département du Var sur les installations de bord de voie évoquées par J. Bérato, la présence italienne dans cette partie de la province avant les années 40 avant J.-C. semble donc, dans l'état actuel des recherches, bien discrète. Si des marchands, commerçants et " investisseurs " ont pu régulièrement y séjourner pour leurs affaires, en revanche, les traccs matćricllcs d'ćtablisscments ruraux italiens en milieu rural paraissent inexistantes et l'hypothèse d'un phénomène précoce d'immigration n'est jamais abordée, alors même que ces territoires - hormis les secteurs placés sous la responsabilité de Marseille relevaient de l'ager publicus de Rome.

\section{LE LANGUEDOC ORIENTAL ET LA VALLÉE DU RHÔNE : L'IMPORTANCE DE MARSEILLE}

En Languedoc oriental et dans la basse vallee du Rhône, les résultats d'une enquête collective menée dans huit microrégions (Valdaine, Tricastin, Haut-Comtat, Alpilles, Uzège, Beaucairois, Vaunage et Lunellois) ont permis à F. Favory, J.-L. Fiches et C. Raynaud de proposer une large synthèse sur l'occupation du sol et le peuplement à la période gallo-romaine.

À partir "d'analyses statistiques multivariées " et en utilisant les ressources d'un système d'information géographique (programme «Archéomedes»), ces auteurs ont notamment constaté un essor particulièrement important de l'habitat rural entre la conquête et le milieu du I ${ }^{\text {er }}$ s. avant J.-C. dans plusieurs microrégions situées dans la basse vallée du Rhône et en Languedoc oriental. Ainsi, entre 120 et 50 avant J.-C., l'Uzège aurait connu un taux de créations d'établissements supérieur à $30 \%$ tandis que le même taux serait à situer, pour les Alpilles, le Beaucairois, la Vaunage et le Lunellois, entre 10 et $30 \%$. Selon ces chercheurs, c'est à Marseille qu'il faudrait imputer la responsabilité de ce phénomène. D'abord en raison de l'existence ancienne d'une zone d'influence, la "Massalie ", s'étendant notamment jusqu'à Avignon, Cavaillon, Glanum (voir déjà dans ce sens : Goudineau, 1976, p. 110-111 ; Py, 1990, p. 190), ensuite parce que Rome lui aurait accordé les territoires des Volques arécomiques et des Helviens (voir déjà : Goudineau, 1976; Gros, 1992, p. 375) ${ }^{5}$, enfin parce qu'elle aurait été la première bénéficiaire de l'élévation de la productivité et de l'accroissement des surplus agropastoraux dans cette région (Favory, Fiches, Raynaud, 1998, p. 88-92).

Si l'hypothèse est séduisante ${ }^{6}$, elle ne traite pas les questions relatives aux modalités de cet essor de l'habitat rural : s'agit-il d'un mouvement spontané engendré par l'essor économique général ? Ces implantations sontelles organisées de manière méthodique? Marseille a-telle pris des initiatives pour favoriser et structurer cette dispersion de l'habitat notamment en initiant la mise en place d'une cadastration gréco-indigène, au moins dans les zones les plus proches de la cité ? Qui occupe ces installations : des indigènes, des Italiens, des Massaliotes? Ce phénomène est-il seulement consécutif à la conquête romaine, du moins pour les zones les plus proches de la cité phocéenne? Pourquoi et comment fixer la date de 120 comme terminus de ce phénomène? Autant de questions qui restent en suspens malgré leurs indéniables intérêts méthodologique et historique. C'est en effet aller peut-être un peu loin qu'imputer à Marseille la fonction de relais de la politique impérialiste de Rome et, ce faisant, de considérer cette ville comme un foyer actif de la romanisation des campagnes! Il semble également risqué de considérer que l'émergence de l'habitat rural serait le signe le plus tangible de la romanisation de l'espace agraire (Favory, Fiches, Raynaud, 1998, p. 95)

\footnotetext{
5. Sur la puissance de Marseille à la fin de l'âge du Fer, on pourra notamment se reporter à D. Roman (1990) qui analyse la situation massaliète à travers les sources antiques.

6. Voir néanmoins sur cette question, les nuances apportées en 1988 par M. Christol et C. Goudineau (1988, p. 89).
} 
sachant que, même si des difficultés demeurent, la ferme protohistorique de Gaule méridionale est une réalité historique de moins en moins contestable. Enfin, à la lecture détaillée de l'ensemble de l'abondante bibliographie consacrée au Languedoc oriental depuis la fin des années 1980, on observe certaines contradictions qui, si elles n'enlèvent rien à la qualité de ces recherches, n'en sont pas moins difficiles à surmonter.

La première est relative à la durée d'occupation des établissements ruraux et à leur fonction. Ainsi, concernant le Lunellois, deux articles précédents avaient par exemple insisté sur la brièveté de leur existence. Entre la conquête et le milieu du ${ }^{\mathrm{er}}$ s. après J.-C., seul l'oppidum d'Ambrussum semblait avoir connu une occupation intense : hors de cette agglomération, le peuplement de la période républicaine paraissait limité et sans grande postérité (Favory et al., 1994, 1996, p. 305-306). De même, dans l'article qu'il a consacré aux centuriations du Languedoc oriental, F. Favory a repris la question de l'habitat dispersé antérieur au milieu du ${ }^{\text {er }} \mathrm{s}$. après J.-C. en Lunellois et a admis, avec C. Raynaud, l'absence d'une colonisation agraire massive antérieure à cette période (Favory, 1997, p. 109). Les rares établissements ruraux détectés dans les zones couvertes par les centuriations Sextantio-Ambrussum et Nîmes A - peut-être finalement contemporaines (datation césaro-triumvirale, ibid., p. 111) ${ }^{7}$ - sont occupés par des indigènes. S'agissant toujours de ces sites tardo-républicains repérés en prospection, l'hypothèse avancée était qu'il ne pouvait s'agir que de gisements ponctuels, " méritant à peine, voire même usurpant, le nom d'habitat " (Favory et al., 1994, 1996, p. 305-306). Habitats, annexes agraires (voir par ex.: Raynaud, 1998), à partir desquelles il paraît difficile, sinon risqué, d'aborder la dynamique du peuplement rural, le discours oscille donc entre les dcux concepts et montre la difficulté d'envisager concrètement les formes de l'occupation du sol de cette période. Il semble pourtant évident que les habitats tardo-républicains ne doivent pas être appréhendés de la même manière que les sites mieux structurés du HautEmpire : structures légères en matériaux périssables et fosses s'opposent ici aux constructions en dur occupant des superficies souvent très supérieures (voir par ex. :

7. L'auteur admet plus loin qu'il faut cependant laisser ouvert le problème de leur datation et croiser les faits archéologiques et archéomorphologiques (Favory, 1997, p. 114).
Bermond, Pellecuer, 1998, p. 59-60, fig. 4 et 5). Observant dans le Vaucluse la rareté des sites de bas de pente et de plaine durant tout le second âge du Fer, M.-E. Bellet avait ainsi avancé une explication pertinente prenant en compte le caractère isolé de ces petites unités ne laissant que peu de traces visibles au sol (Bellet, 1990, p. 36). De plus, même si les annexes agraires sont aujourd'hui une réalité tangible, ce concept ne doit pas masquer les difficultés que nous rencontrons face à des vestiges mal conservés ou inhabituels. Peut-être que le terme plus neutre de «site de nature indéterminée» pourrait-il mieux exprimer l'état transitoire des connaissances actuelles.

Quoi qu'il en soit, les deux concepts - habitat et annexe agraire - peuvent être complémentaires mais n'expriment pas forcément les mêmes réalités: le premier peut être le signe d'une réelle croissance démographique et/ou d'un phénomène de dispersion de l'habitat groupé ; le second exprime peut-être seulement un essor économique, voire une évolution radicale de l'exploitation des sols, ce qui est tout à fait différent, surtout dans une perspective diachronique. Pourtant, dans la carte qui présente le taux de création d'établissements de 120 à 50 avant J.-C., le Lunellois fait partie des microrégions les plus dynamiques avec un taux de création de $13 \%$ (Favory, Fiches, Raynaud, 1998, p. 88-89), mais en définitive s'agit-il d'habitats ou d'annexes agraires?

Un peu plus au nord, en Vaunage (Favory et al., 1998, p. 220-221), une trentaine d'établissements apparaissent après la fin du II ${ }^{\mathrm{e}} \mathrm{s}$. avant J.-C. et amorcent la diffusion du peuplement dans la plaine et sur les coteaux ; ici, l'initiative pourrait en revenir très clairement aux communautés indigènes locales établies durant tout l'âge du Fer sur un réseau très dense d'oppida (Py, 1990). À l'inverse du secteur lunellois, la réussite et la pérennité de cette première étape de dispersion apparaissent nettement, mais en l'absence d'une présentation détaillée des artefacts trouvés sur ces sites on peut se demander si les éléments chronologiques sont réellement homogènes et postérieurs au dernier quart du $\mathrm{II}^{\mathrm{e}} \mathrm{s}$. ? Pourquoi en effet considérer que ce phénomène aurait été consécutif à la conquête ? Pourquoi encore une fois présenter la dispersion de l'habitat comme contemporaine du rattachement de la Transalpine à Rome alors qu'elle semble finalement commune à toute la Gaule durant l'âge du Fer? Imputer à Marseille la responsabilité de cet essor de 
l'habitat rural dispersé, c'est finalement réfuter l'idée selon laquelle les communautés indigènes gauloises étaient tout à fait capables de se développer de manière autonomne. On lira à cet égard les pages éclairantes qu'O. Buchsenschutz (1997) a consacré aux parcellaires et à l'occupation du sol de l'âge du Fer en France septentrionale pour se convaincre, s'il le faut, de la profondeur des blocages historiographiques inhérents au concept méridional de la "Civilisation des oppida».

Enfin, d'une manière plus générale et si l'on accepte l'hypothèse du rôle prépondérant de Marseille, comment expliquer l'existence des centuriations romaines anciennes ${ }^{8}$, peut-être antérieures au milieu du $\mathrm{I}^{\mathrm{er}}$ s. avant J.-C., reconnues en Languedoc oriental ? Que faire par exemple des réseaux Forum Domitii A, SextantioAmbrussum, Nîmes C - qui serait antérieur au Nîmes A et à propos duquel J.-L. Fiches et F. Favory avancent l'hypothèse d'un système parcellaire préromain (Fiches, 1993b, p. 102 ; 1995, p. $28-29$ et p. 36 ; Favory, 1997) - et Orange D, que J.-L. Fiches situe dans la même phase chronologique ancienne que Béziers B (Fiches, 1993b, p. 103) ${ }^{9}$ ? Serions-nous en présence de systèmes élaborés et construits par Rome et utilisés par Marseille et les indigènes à leur seul bénéfice ? Peut-il s'agir de systèmes indigènes identiques à ceux observés en Chevelue, voire romano-indigènes ? Assurément, les recherches en cours sur la genèse et la chronologie exacte des cadastres en Gaule transalpine pourraient beaucoup apporter au débat.

Mais revenons à la question de l'habitat dispersé. Qu'en est-il plus précisément dans la vallée du Rhône, où le taux de création d'établissements de 120 à 50 avant J.-C. est inférieur à $10 \%$ ? Pour le Tricastin, T. Odiot n'a pu détecter qu'un seul site, mais le contexte de la découverte - sous une couche d'alluvions de $1,80 \mathrm{~m}$ d'épaisseur - pose le problème de la fiabilité d'une carte archéologique dans la plaine rhodanienne (Odiot, 1994,

8. Pour une présentation synthétique des systèmes cadastraux reconnus en Gaule du Sud, voir G. Chouquer, 1993.

9. Notons cependant que J.-L. Fiches fait preuve d'une grande prudence et ne donne aucune datation précise aux phases cadastrales qu'il expose dans son tableau des limitations romaines en Narbonnaise. Il s'agit en effet d'une proposition de chronologie relative. Notre interrogation sur les centuriations n'a pour seule ambition que de soulever un problème général touchant à la finalité pratique d'un cadastre dépourvu d'un réseau d'habitat, même si nous n'ignorons pas que ces systèmes ont également d'autres fonctions, et notamment fiscales. p. 90 ; Berger et al., 1997, p. 179-180 et fig. 16). Il se pourrait en effet que d'autres sites contemporains soient disséminés dans cette zone, ce qui changerait singulièrement l'interprétation de la dynamique du peuplement local. Pour la période pré-augustéenne, les recherches ont montré la présence de six sites regroupés dans le même secteur de la plaine de Pierrelatte. Les données matérielles livrées par les prospections et les observations faites lors d'aménagements agraires récents indiquent que l'on a affaire à des établissements construits en matériaux périssables, comportant des structures " en creux " du type fosses et fossés livrant $\mathrm{du}$ mobilier italique en relative abondance. T. Odiot s'interroge d'ailleurs à juste titre sur le caractère colonial de ces implantations qui ne parviendront pas à se maintenir au-delà de la période augustéenne (Odiot, 1994, p. 91).

En Vaisonnais, J.-C. Meffre et J.-C. Leyraud ont travaillé sur un corpus très important de sites; à l'époque augustéenne, 97 implantations nouvelles apparaissent et le réseau sera complété par 90 autres créations ultérieures. Pour la période antérieure, les données sont presque insignifiantes, ce qui pose la question d'une occupation effective de cette région au second âge du Fer et durant la période tardo-républicaine (Meffre, 1994, fig. 3). On peut néanmoins se demander si cette phase n'est pas tout simplement gommée par le parti pris qui consiste à considérer que les céramiques à vernis noir et les amphores Dressel 1 relèvent encore d'une chronologie augustéenne (ibid., p. 124-125) et doivent, au mieux, être considérées comme résiduelles. Il ne peut en effet y avoir, sauf exception, de céramique et encore moins d'amphores anciennes sur des créations ex nihilo et l'on ne peut pas dater les débuts de l'occupation d'un habitat rural en s'appuyant sur des remblais et des niveaux de circulation issus de fouilles d'agglomérations occupées sur la longue durée et souvent d'origine protohistorique. Sur ces dernières, le mobilier amphorique est très important et reste très présent même lorsqu'il n'est plus commercialisé : à Lattes, l'amphore Dressel 1 est ainsi représentée dans les couches d'occupation et de remblais jusqu'à la fin du I ${ }^{\text {er }}$ s. après J.-C. (Fiches et al., 1994 , p. 371) et, d'une manière générale, on sait les multiples réutilisations dont les amphores ont fait l'objet. Callender y avait consacré une petite partie de son ouvrage. En définitive, pour une même tranche chronologique, le faciès de fondation des sites ruraux sera donc 
différent de celui des agglomérations, c'est d'ailleurs ce qui en fait son principal intérêt. Enfin, concernant plus largement la question de la datation intrinsèque des principaux fossiles directeurs que constituent amphores et céramiques fines, les travaux d'A. Desbat et des chercheurs lyonnais sur l'arrêt de la diffusion des Dressel la dans la vallée du Rhône ont bien montré qu'elles n'étaient plus diffusées après les années 50-40 avant J.-C. (Desbat et al., 1989 ; Desbat, 1998 ; Lemaître et al., 1998; Maza, 1998), tout comme les céramiques à vernis noir campaniennes. La présentation des contextes lyonnais et leur mise en perspective avec les données provenant des épaves méditerranéennes chargées de Dressel 1, mais aussi avec le dossier des marques consulaires ou avec les fouilles de Carthage et des camps du limes germanique, constituent désormais une preuve irréfutable de ce phénomène (voir en dernier lieu : Poux, 1999, p. 34-38) et invitent donc les tenants des chronologies basses à réviser une partie de leurs hypothèses.

Ainsi, en Vaisonnais, les amphores récoltées en prospection sont essentiellement représentées par des Dressel $1{ }^{10}$ et sont, comme la céramique campanienne, rattachées à la période augustéenne. À l'inverse, les chercheurs travaillant dans la région nord d'Orange, située immédiatement à l'ouest du Vaisonnais, s'appuient sur la céramique à vernis noir pour dater les sites dans la première moitié du I ${ }^{\mathrm{er}}$ s. avant J.-C. (Bellet et al., 1994, p. 136). Si comme le pense M. Py, le faciès céramique du Languedoc oriental est marqué par une diffusion très tardive des céramiques italiennes à vernis noir jusque vers le dernier quart du I ${ }^{\text {er }}$ s. avant J.-C., faut-il généraliser cette observation à la rive gauche du Rhône et, pour être plus radical, ne faudrait-il pas remettre ce schéma en question comme cela a été fait récemment (Genty, Feugère, 1995, p. 176) ? Ces quelques remarques n'enlèvent rien à la grandc qualité du dossier vaisonnais et au travail de fond réalisé par J.-C. Meffre dans le cadre du programme "Archéomedes "; on voudrait simplement insister sur les divergences qui existent souvent entre archéologues pour dater le mobilier de surface et sur

10. L'auteur ne précise pas s'il s'agit de Dressel la et/ou b mais même en considérant que ces amphores se rattachent à la dernière "variante ", la chronologie doit nécessairement être élargie à la première moitié du $\mathrm{I}^{\mathrm{er}} \mathrm{s}$. avant J.C., comme le démontre le dossier des marques consulaires les plus anciennes connues sur ce type d'amphore : Agen, Vallromanes, Rodez, Rome, Burriac et Carthagène (fin II's. avant J.-C./90 avant J.-C.). l'importance d'une confrontation constante des résultats et hypothèses proposés. Ici, une simple révision d'une partie des sites du catalogue ferait peut-être apparaitre des sites occupés durant la première moitié du $\mathrm{I}^{\mathrm{er}} \mathrm{s}$. avant J.-C. ce qui, là aussi, pourrait finalement faire basculer le Vaisonnais dans le groupe des microrégions les plus dynamiques.

Quoi qu'il en soit, le retard enregistré dans ces régions de la moyenne vallée du Rhône est actuellement interprété comme le résultat logique des révoltes indigènes successives qui, c'est vrai, ont surtout touché cette partie de la province (Clavel-Lévêque, 1988) ${ }^{11}$ : l'exploitation multiforme qu'elles auraient subie aurait entraîné des affrontements empêchant l'émergence de l'habitat rural (Favory, Fiches, Raynaud, 1998, p. 95) et cette rareté des sites corroborerait donc l'hypothèse selon laquelle les troubles politiques et militaires auraient eu des effets néfastes sur l'occupation du sol. Compte tenu des réserves émises plus haut sur l'appréciation de la datation des sites utilisés dans le corpus, on peut toutefois s'interroger sur la validité de cette hypothèse, d'autant que finalement, si exploitation multiforme il y a eu, il faudrait mieux en définir les caractéristiques : à contrario, la localisation des révoltes pourrait même permettre de localiser les principaux foyers d'implantation italienne durant la période tardorépublicaine.

De ces analyses, on retire donc l'impression que la présence romaine à l'est de l'Hérault et jusqu'au Rhône fut - à l'exception du relais routier de Forum Domitii, fondé au moment de l'aménagement de la voie Domitienne en 118 avant J.-C. - presque inexistante, du moins dans les campagnes car il $y$ avait très certainement, comme en Provence, des marchands romains et italiens, voire des artisans dans les agglomérations indigènes comme Nîmes, Lattes, Ambrussum ou Murviellès-Montpellier. Des dérivées de campanienne $\mathrm{C}$, dont l'origine régionale était supposée (Py, 1990, p. 227), ont par exemple été produites sur l'oppidum indigène de Briginno/Brignon (Gard), au sein du pays des Volques arécomiques, par un petit groupe d'artisans

11. Concernant les implantations italiennes, le cas le plus emblématique, rapporté par Dion Cassius, est celui de l'échec de la colonie de Vienne - peut-être fondée par Tiberius Claudius Néron sur ordre de César - et dont les vétérans furent chassés de leurs terres par les Allobroges (voir en dernier lieu : Chastagnol, 1997, p. 54). 
siciliotes ${ }^{12}$. Pour les campagnes, l'absence d'inscription tardo-républicaine latine ${ }^{13}$ et l'analyse de J.-L. Fiches sur la répartition des tombes et des monuments lapidaires indigènes à inscription gallo-grecque (Fiches, 1989, 1993a et aussi Lejeune, 1985, p. 16) constituent des éléments de poids en faveur d'une absence de population italienne. On peut d'ailleurs ajouter à ces arguments celui de la fréquence relativement élevée des occurrences du gentilice Marius dans la cité des Arécomiques (Christol, 1987, p. 212-213 ; 1992, p. 187-189) qui serait l'indice de promotions accordées à des Volques par cet imperator de la fin du II ${ }^{e}$ s. avant J.-C. ${ }^{14}$. Compte tenu de ces observations et dans l'état actuel des recherches, on considérera donc que la présence italienne en milieu rural ne sera effective, dans ces régions, qu'à partir de l'époque césaro-triumvirale qui correspond à la grande période des fondations coloniales en Gaule du Sud (Christol, 1994 ; Favory, 1997, p. 116-117).

Ainsi donc, après avoir conquis la Gaule transalpine, Rome ne se serait finalement intéressée qu'aux terres situées à l'ouest de l'étang de Thau et de la vallée de l'Hérault, confiant à Marseille, comme le pensaient déjà C. Ebel et C. Goudineau à la fin des années 1970, la garde des terres situées entre l'Hérault et les Alpes avant les événcments consćcutifs à la gucrrc des Gaulcs. Si l'on peut considérer ce schéma comme valable, dans l'état actuel des connaissances, on doit cependant faire remarquer que certaines contradictions apparentes ne sont pas résolues, notamment en ce qui concerne la chronologie d'un certain nombre de sites ruraux et la question fondamentale des centuriations anciennes (Fiches, 1993b). On doit également s'interroger - mais cela n'entre pas dans notre propos - sur le statut du territoire arécomique et des terres de la vallée du Rhône entre la conquête et les événements des années 70 avant

12. F. Souq, Brignon, Serre de Brienne, Bilan scientifique de la région Languedoc-Roussillon 1994, p. 88. Le four dans lequel étaient cuites ces céramiques était de forme carrée, comportait un pilier central soutenant une sole perforée et les parois étaient construites en brique crue. Sa technologie relèverait de modèles gréco-italiques. On doit également signaler que le toit de la maison abritant cette activité artisanale était recouvert de tegulae (80-60 avant J.C.).

13. On connaît, en revanche, de rares exemples d'inscriptions trouvées en contexte urbain comme par exemple une dédicace provenant d'Avignon qui pourrait dater de la première moitié ou du milieu du $\mathrm{I}^{\text {er }}$ s. avant J.-C. (CII XII, 1028).

14. Voir également la présence d'un portrait de Marius à Murviel-lèsMontpellier, daté des années 60 avant J.-C. par J.-C. Balty (1981).
J.-C. Enfin, mais nous y reviendrons, l'existence du mausolée d'Argenton/Le Fugeret (voir supra et Bérard, Roth Congès, 1997), daté du deuxième quart du $\mathrm{I}^{\mathrm{er}} \mathrm{s}$. avant J.-C. et installé à $1300 \mathrm{~m}$ d'altitude, pose encore une fois, si l'on accepte la chronologie haute qui lui a été assignée, le problème de la présence de groupes d'immigrés italiens installés dans des zones isolées et donc de la validité des modèles généraux qui peuvent être dégagés à partir des seules données de l'occupation du sol. À cet égard, la mention de Cicéron relative à la propriété que Quinctius possédait chez les Sebaginniens de la vallée de la Durance et le contexte socio-économique provincial qu'il décrit constituent aussi des éléments contradictoires au tableau brossé à partir des seuls résultats archéologiques.

\section{LA TRANSALPINE OCCIDENTALE (LANGUEDOC OCCIDENTAL ET ROUSSILLON)}

Dans ces régions qui correspondent à la partie occidentale de la province de Transalpine, la situation est très différente de celle observée ailleurs ${ }^{15}$. Les sites ruraux qui livrcnt du mobilier antérieur au milieu du $\mathrm{I}^{\mathrm{er}}$ s. avant J.C. sont en effet nombreux (350-400, of. Mauné, à paraître) et l'essor important de l'archéologie extensive dans cette région et la prise en compte - dans le cadre des volumes de la Carte archéologique de la Gaule actuellement en préparation - de l'ensemble de la documentation publiée ou pas devraient permettre de tripler ce premier inventaire. Le contexte historique, avec la fondation de la colonie romaine de Narbonne en 118 avant J.-C. (Gayraud, 1981), pourrait expliquer, a priori, ce phénomène, mais il est paradoxal de constater que le

15. Ces données ayant déjà fait l'objet de présentations synthétiques (Mauné, 1998b et à paraître), on abordera cette problématique de manière transversale, sans reprendre, pour chaque secteur, le détail des résultats. Enfin, la question de l'annexion précoce, à partir de l'Espagne et avant la date de 118 avant J.-C., de cette partie de la province (thèse avancée par Mommsen et notamment reprise par C. Ebel en 1976) ne sera pas traitée en l'absence de tout élément matériel nouveau à verser à ce dossier (Mauné, Chazelles, 1998). Sur cette question voir en dernier lieu C. Rico, 1997 : notamment sur le problème d'un bornage de la voie permettant de relier Emporion au Rhône avant la conquête de 118 avant J.C. (p. 147-152) et à propos de l'organisation de la province de Transalpine (p. 161-162). Pour un résumé très utile sur le statut des cités de la Gaule transalpine/ Narbonnaise, voir A. Chastagnol, 1997. 
secteur narbonnais est justement celui où l'on a le moins avancé dans cette problématique. Toutefois, les travaux de prospections systématiques actuellement engagés sur cette zone par deux équipes - l'une dans le sudNarbonnais, l'autre sur le territoire de l'oppidum de Montlaurès - permettront sans doute, à terme, de mieux appréhender l'occupation du sol de ce secteur et peutêtre même les plus anciens établissements ruraux italiens de Gaule transalpine. Plus globalement, on doit également souligner qu'une partie des établissements ruraux pris en compte sont antérieurs au dernier quart du $\mathrm{II}^{\mathrm{e}} \mathrm{s}$. avant J.-C. et relèvent donc d'une dynamique préromaine. Sur un pré-inventaire récemment réalisé, ils représenteraient entre 10 et $15 \%$ des $350 / 400$ sites actuellement connus pour les seuls départements de l'Aude et des Pyrénées-Orientales ainsi que pour la moitié occidentale de l'Hérault. Cette observation conduit à accepter l'idée selon laquelle l'exploitation du sol à partir d'un réseau de fermes dispersées n'est pas forcément à mettre au compte de l'annexion de la Gaule transalpine par Rome en 118 avant J.-C. Les Gaulois du sud, comme ceux du nord d'ailleurs, mettaient les sols en valeur à partir d'unités rurales familiales de type ferme, réparties sur le territoire d'agglomérations perchées ou non. D'après les données provenant de la moyenne vallée de l'Hérault, cette génération de sites semble disparaître entre le dernier quart du $\mathrm{II}^{\mathrm{e}} \mathrm{s}$. et le milieu du I ${ }^{\mathrm{er}} \mathrm{s}$. avant J.-C. ; quelques installations réussissent cependant à se maintenir jusqu'au $\mathrm{II}^{e} \mathrm{~s}$. après J.-C., voire jusqu'à la fin de l'Antiquité (Mauné, 1998a, p. 57-61). À partir de la fin du $\mathrm{II}^{e} \mathrm{~s}$. et surtout durant la première moitié du $\mathrm{I}^{\mathrm{er}} \mathrm{s}$. avant J.-C., on assiste, parallèlement à ce phénomène, à l'apparition de très nombreux sites ruraux.

\section{LE POIDS DE L'HABITAT RURAL D'ÉPOQUE TARDO-RÉPUBLICAINE DANS L'HISTOIRE DES CAMPAGNES DE TRANSALPINE OCCIDENTALE}

Pour bien saisir l'importance de cette phase ancienne du peuplement rural, on doit d'abord faire remarquer que c'est dans cette période, comprise entre la conquête et la période césarienne, que la plupart des grands établissements ruraux à occupation longue de type villa trouvent leur génèse: dans la moyenne vallée de l'Hérault, pratiquement toutes les grandes villae remontent à cette phase tardo-républicaine (Feugère,
Rouquette, 1985 ; Mauné, à paraître). Sur la rive septentrionale de l'étang de Thau, le premier état de la future villa des Près-Bas est antérieur ou contemporain au milieu du I ${ }^{\mathrm{er}} \mathrm{s}$. avant J.-C. et les recherches menées sur d'autres grands établissements ruraux de ce secteur confirment cette observation (Bermond et al., 1989; Lugand, Pellecuer, 1994 ; Bermond, Pellecuer, 1997, 1998). Autour de Béziers (Giry, Fedière, 1978, 1979) et dans la vallée de la Thongue (Bermond, 1992, p. 8), les recherches de terrain montrent la même réalité : de toute évidence, la période comprise entre le milieu du II ${ }^{e}$ et le milieu du I ${ }^{\text {er }}$ s. avant J.-C. fut une étape importante et décisive dans l'histoire de l'occupation du sol de cette région. Mais cette genèse ancienne concerne également des établissements modestes ou moyens qui constituent ici la majorité des implantations rurales antiques. Toujours dans la partie nord-orientale de la région de Béziers (moyenne vallée de l'Hérault), $25 \%$ des 200 sites occupés durant la première moitié du $\mathrm{II}^{\mathrm{e}} \mathrm{s}$. après $\mathrm{J}$.-C. remontent ainsi à la première moitié du ${ }^{\text {er }} \mathrm{s}$. avant $\mathrm{J}$-C. . (Mauné, 1998a, p. 502-503). Cependant, certaines installations connurent un échec total et furent abandonnées avant le milieu du $\mathrm{I}^{\mathrm{er}}$ s. avant J.-C. (Mauné, 1998a, p. 439, p. 483-485 et p. 494-496); ce phénomène a surtout été mis en évidence dans la région de Ruscino, dans le massif des Albères (Kotarba, 1995 ; Comps, Kotarba, 1997), mais ne concerne au maximum qu'un établissement sur cinq.

Plus largement encore, une dynamique tout à fait identique a également été observée en Lauragais (Passelac, 1983, 1994), dans le couloir audois en Minervois (Rancoule, 1987, 1992), dans la basse vallée de l'Aude (Mauné, Chazelles, 1998), dans les Corbières (Solier, 1992) et également en Roussillon (Comps, Kotarba, 1997). Dans ces régions, la période comprise entre la fin du II ${ }^{e}$ s. et le milieu du I ${ }^{\mathrm{er}} \mathrm{s}$. est donc marquée par l'apparition et le développement rapide d'un important réseau d'établissements ruraux dont la réussite est manifeste. Les témoins matériels que livrent ces sites ne laissent aucun doute sur leur datation et leur fonction d'habitat : amphores gréco-italiques tardives et Dressel la ancienne, Dressel la, céramique campanienne $\mathrm{A}, \mathrm{B}$ et $\mathrm{C}$, céramique commune italique, céramiques espagnoles (côte catalane et claire peinte de type sombrero de copa) et céramique modelée plaident tous en faveur d'une chronologie assurément antérieure au milieu du $\mathrm{I}^{\mathrm{er}} \mathrm{s}$. av. J.-C. (fig. 2), tandis que plusieurs fouilles de sauvetage 

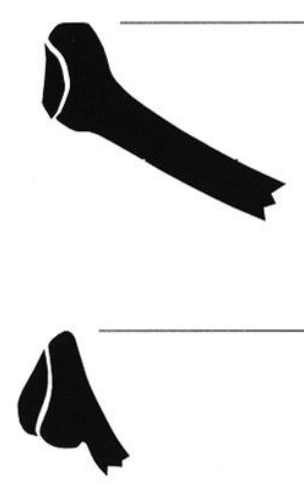

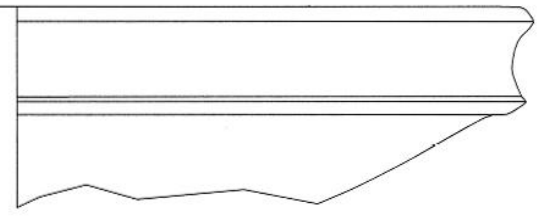

1

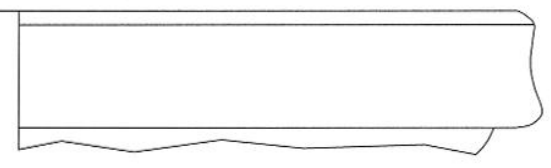

2
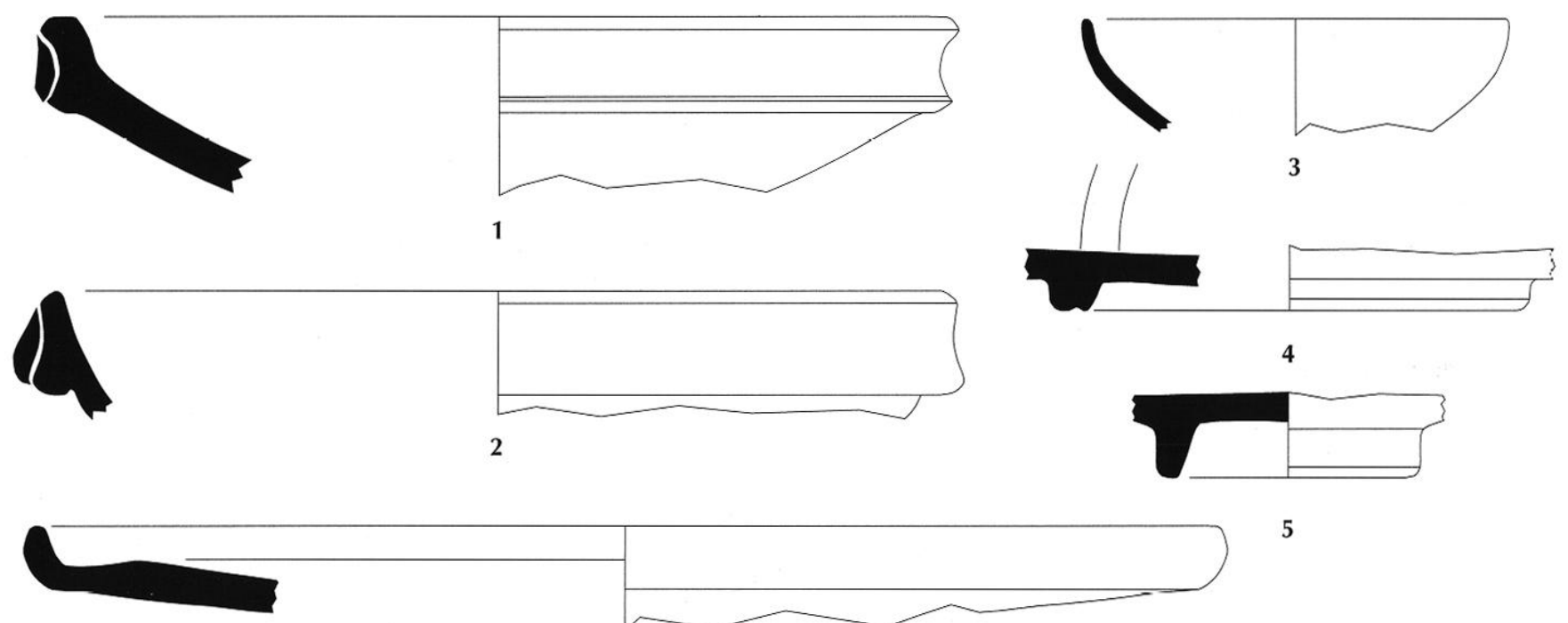

5

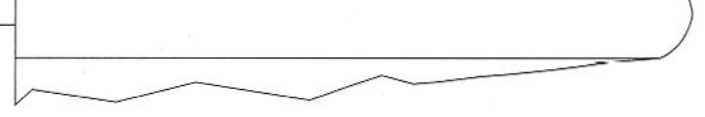

6

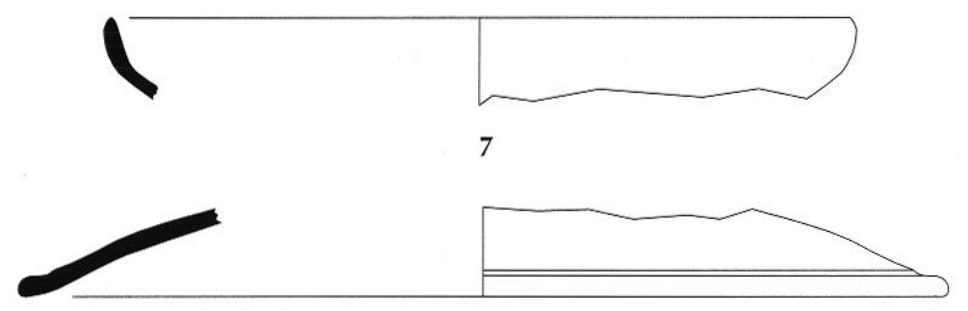

8

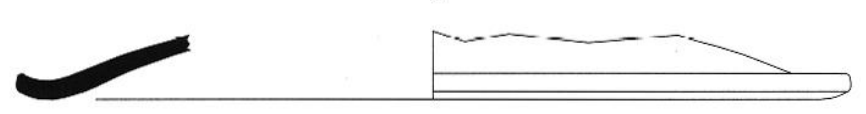

9
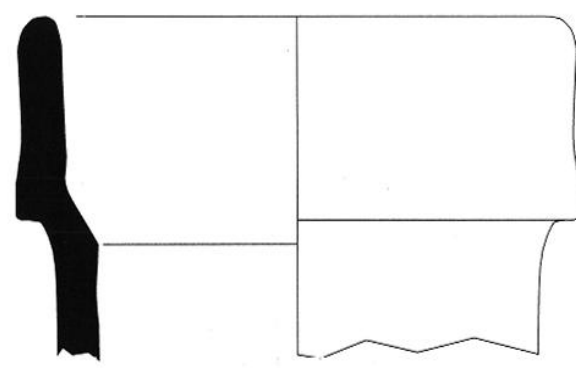

12
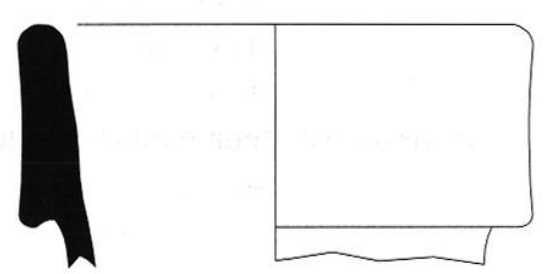

13

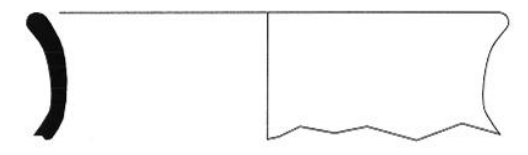

10

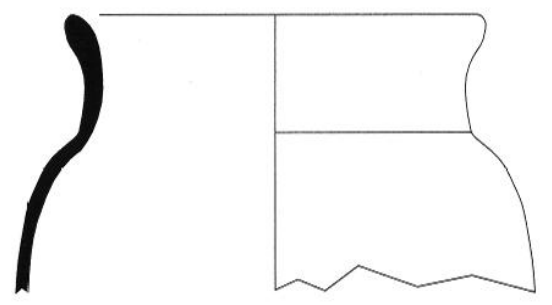

11

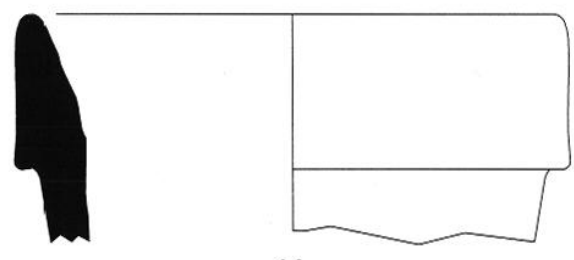

14

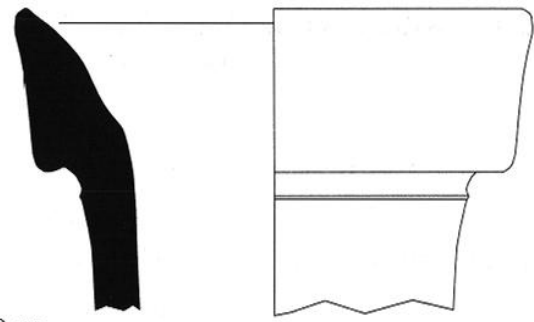

$10 \mathrm{~cm}$
15

Fig. 2 - Exemple d'un lot de mobilier céramique provenant de Virins à Saint-Pargoire (Hérault), établissement rural fondé dans la première moitié $d u I^{r}$ s. avant J.-C. : 1, imitation régionale de mortier italique; 2,8 , 9, céramique commune italique; 3, 7, campanienne A; 4-6, campanienne $C$ (imitations régionales probables); 10,11, céramique non tournée ; 12-15, amphores Dressel 1b et 1a. Échelle: 1/3 (dessin S. Mauné). 
ont confirmé la présence de vestiges appartenant à des fermes (Mauné, à paraître) : enclos fossoyés, silos, dépotoirs, foyers, murs en pierre ou en adobe, dolia, meules en basalte... Un certain nombre de sites ont également livré des monnaies qui permettent de confirmer cette chronologie: deniers républicains, monnaies " à la croix », petits bronzes « au taureau passant » et " au taureau cornupète ", bronzes ibériques, monnaies de la région de Béziers/Narbonne, etc. La masse des données disponibles est impressionnante et l'un des objectifs prioritaires que s'est fixé le nouveau projet collectif de recherche "Dynamique et formes de l'occupation du sol en Transalpine occidentale aux $\mathrm{II}^{\mathrm{e}}$ et $\mathrm{I}^{\mathrm{er}} \mathrm{s}$. av. J.-C. » est d'ailleurs de traiter et de publier rapidement l'ensemble de cette documentation, issue des prospections et des fouilles, afin de la soumettre, en toute transparence, à l'appréciation de la communauté scientifique.

Enfin, et pour en terminer avec l'occupation du sol, on doit également souligner pour cette période l'essor des agglomérations indigènes qui atteignent souvent leur extension maximale : c'est par exemple le cas des vieux oppida d'Aumes, de Magalas, d'Ensérune (Hérault) ou de Montlaurès (Aude), des oppida-marchés (La Lagaste, Bouriège...) du secteur audois (Rancoule, Schwaller, 1994), mais aussi des villages de plaine de la moyenne vallée de l'Hérault (Mauné, 1998a, p. 27-32). Peut-être faut-il expliquer ce phénomène par l'augmentation du volume des échanges commerciaux et plus largement le considérer comme caractéristique d'une intense croissance économique: agriculture, exploitation des ressources minières, transports...

C'est donc peut-être l'amplification du phénomène précoce de dispersion de l'habitat indigène et l'intérêt de Rome pour les richesses agricoles de Transalpine occidentale qui peuvent expliquer l'augmentation très nette du nombre de fermes à partir de la fin du $\mathrm{II}^{\mathrm{e}} \mathrm{s}$. S'il reste encore très difficile, voire impossible, de préciser site par site l'origine, indigène ou étrangère (italienne en l'occurrence), des occupants de ces établissements ruraux, il faut peut-être penser qu'ils étaient d'origines ethnique et sociale assez diverses; seul le territoire de la colonie romaine de Narbonne ayant fait l'objet - mais nous l'avons déjà souligné - d'une déduction de citoyens romains en 118 avant J.-C. Ailleurs, on ne peut en effet imaginer que Rome se contentât d'exploiter l'ager publicus à partir de quelques habitats groupés ou de points d'appui militaires qui restent d'ailleurs à localiser. Il est probable que la pacification et l'exploitation des terres aient été confiées à des Italiens (possessores, colons viritim) désireux de se tailler des domaines dans la nouvelle province mais aussi à des indigènes en voie de romanisation (élites locales, auxiliaires promus ou récompensés). En effet, à moins de supposer une brusque explosion démographique du monde indigène à la fin du second âge du Fer, on peut penser que cette multiplication du nombre de sites fut alimentée - dans des proportions encore impossibles à fixer - par une immigration italienne précoce plus ou moins régulière entre la conquête et les années 50-40 avant J.-C. Dans cette hypothèse, Narbonne, comme d'autres ports de Transalpine, a pu constituer le point d'arrivée et de départ de petits groupes d'Italiens, attirés ici par les activités commerciales florissantes et de belles opportunités foncières. Pour l'Espagne voisine, P. Le Roux a d'ailleurs insisté sur la diversité des aspects de la conquête romaine en soulignant l'afflux d'immigrants italiens venus s'installer sur des terres nouvelles sans y avoir été véritablement conviés par les autorités romaines (Le Roux, 1982, p. 37). En considérant cette hypothèse, tout à fait valable pour la Gaule méridionale, on peut aller plus loin et imaginer une relation entre la proximité de la province romaine d'Espagne citérieure et l'apparition du réseau d'établissements ruraux tardo-républicains mis en évidence par J. Kotarba dans la plaine du Roussillon; l'ancienneté et la nature des liens qui, à la période augustéenne, semblent unir les Italiens installés de part et d'autre des Pyrénées pouvant être révélateurs de ce phénomène (Christol, Plana-Mallart, 1997, 1998 ; Christol, Fedière, 1999 ; Christol, à paraître).

C'est peut-être alors l'ancienneté de ces installations, du moins pour celles ayant réussi à passer le cap des guerres civiles et des derniers soubresauts des années 70 avant J.-C. en Transalpine occidentale (Clavel-Lévêque, 1988), qui peut expliquer leur réussite ultérieure. Il est en effet fort probable que la proximité de Narbonne et, pour l'actuel Roussillon, de la province d'Espagne citérieure, l'ancienneté des relations commerciales entre Italiens et indigènes (Rancoule, 1985 ; Bats, 1986) aient pu assurer à cette phase de peuplement des bases économiques solides et une certaine pérennité. Installés sur des secteurs agricoles favorables, disposant de la proximité de sources et de rivières et bénéficiant peut-être aussi de très vastes espaces propices à la polyculture et à l'élevage 
extensif, ces établissements avaient vraisemblablement plus d'atouts pour réussir que leurs homologues coloniaux de l'époque césaro-triumvirale ou du HautEmpire. On pourrait ainsi résumer la situation en une phrase : les premiers arrivés furent les mieux servis. De fait, bien souvent ces sites assumèrent durant toute l'Antiquité, et pour certains jusque dans le courant du Moyen Âge, une fonction évidente de pôle rural majeur (Mauné, 1998a, p. 39-56 ; Bermond, Pellecuer, 1998) et il semble que l'on tienne là une piste de recherche essentielle pour les débuts de l'économie domaniale en Gaule transalpine/ Narbonnaise.

\section{LA QUESTION DES CENTURIATIONS PRÉCOCES}

Cette phase de peuplement, dont on ne distingue sans doute que les signes les plus visibles, peut être mise en parallèle avec plusieurs systèmes cadastraux reconnus conjointement par divers chercheurs (M. Guy, M. ClavelLévêque, G. Chouquer, F. Favory, A. Pérez) et dont on admet aujourd'hui qu'ils peuvent remonter aux décennies qui suivirent la conquête. Pour Rome, l'utilité de vastes opérations d'arpentage semble liée, d'abord et surtout, à une appréhension globale de l'espace conquis (Clavel-Lévêque, 1990, p. 74) débouchant ensuite sur l'imposition d'un tribut correspondant en fait tout simplement à l'assiette de l'impôt. Après la fondation de Narbonne, la mise en place d'une centuriation en Narbonnais et l'installation des colons, il s'agissait de s'assurer le contrôle économique et politique de la région avec, très certainement, des adaptations aux conditions politiques microrégionales. Ainsi, dans la moyenne vallée de l'Hérault, on a pu observer que les territoires vivriers des agglomérations préromaines ne présentaient pas de trace parcellaire isocline au Béziers B : l'implantation des nouveaux habitats ruraux tenant compte de ces entités et s'effectuant sur leurs marges, comme s'il s'agissait de laisser une certaine autonomie à ces centres indigènes tout en encadrant leur développement (Mauné, 1996). L'apparition de ces établissements est d'ailleurs mise en relation avec la présence de structures agraires (chemins, limites de parcelles, talus...) isoclines à la première centuriation biterroise, dite Béziers B $\left(\mathrm{N} .32^{\circ} \mathrm{E}\right.$.), et leur implantation privilégiée - sur ou contre un cardo ou un decumanus, à l'angle d'une centurie - semble révéler un lien étroit

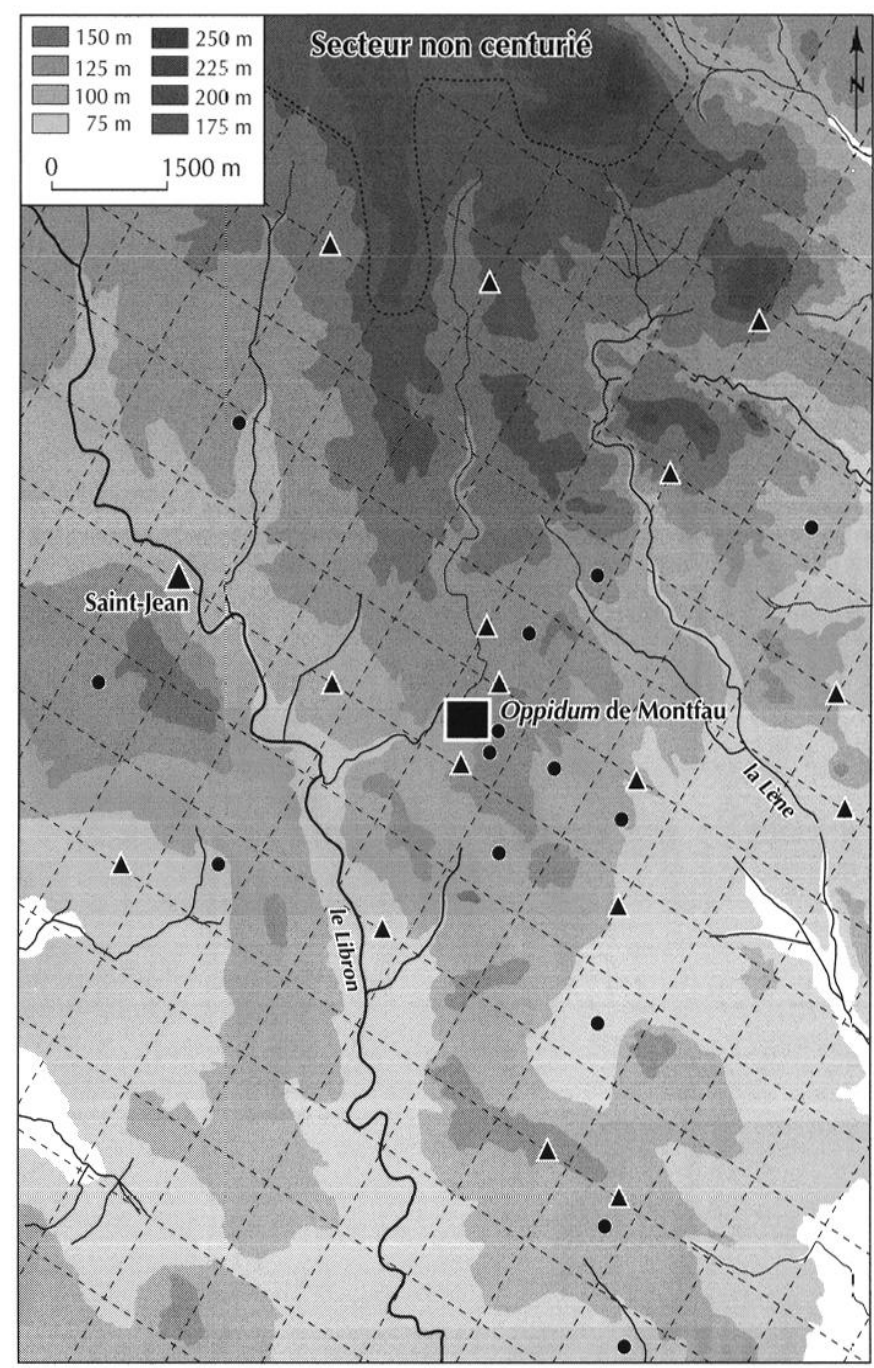

Fig. 3 - Exemple des relations entre les cadastres tardo-républicains et le réseau des établissements ruraux en Transalpine occidentale: la centuriation précoloniale Béziers $B$ et l'occupation du sol de la moyenne vallée du Libron (Hérault, nord-Biterrois) dans la première moitié du Irs. avant J.-C. Cercles pleins, sites qui n'entretiennent pas de relation topographique avec la grille de la centuriation Béziers $B$; triangles, sites installés sur ou contre un decumanus ou un cardo, ou à l'angle d'une centurie (d'après Dodinet, 1985 et Vidal et al., 1995, fig. 1, plans complétés).

avec ce système. En définitive, et bien qu'il s'agisse encore d'une hypothèse de travail, on a bien l'impression que Rome laissa à un certain nombre d'agglomérations indigènes la capacité vivrière nécessaire au maintien de leur développement. Cette observation induit-elle pour autant l'existence de statuts spécifiques? Nous aurons l'occasion de revenir sur cette question.

Quoi qu'il en soit, le lien qui semble exister entre les centuriations précoces et les habitats ruraux a surtout été 

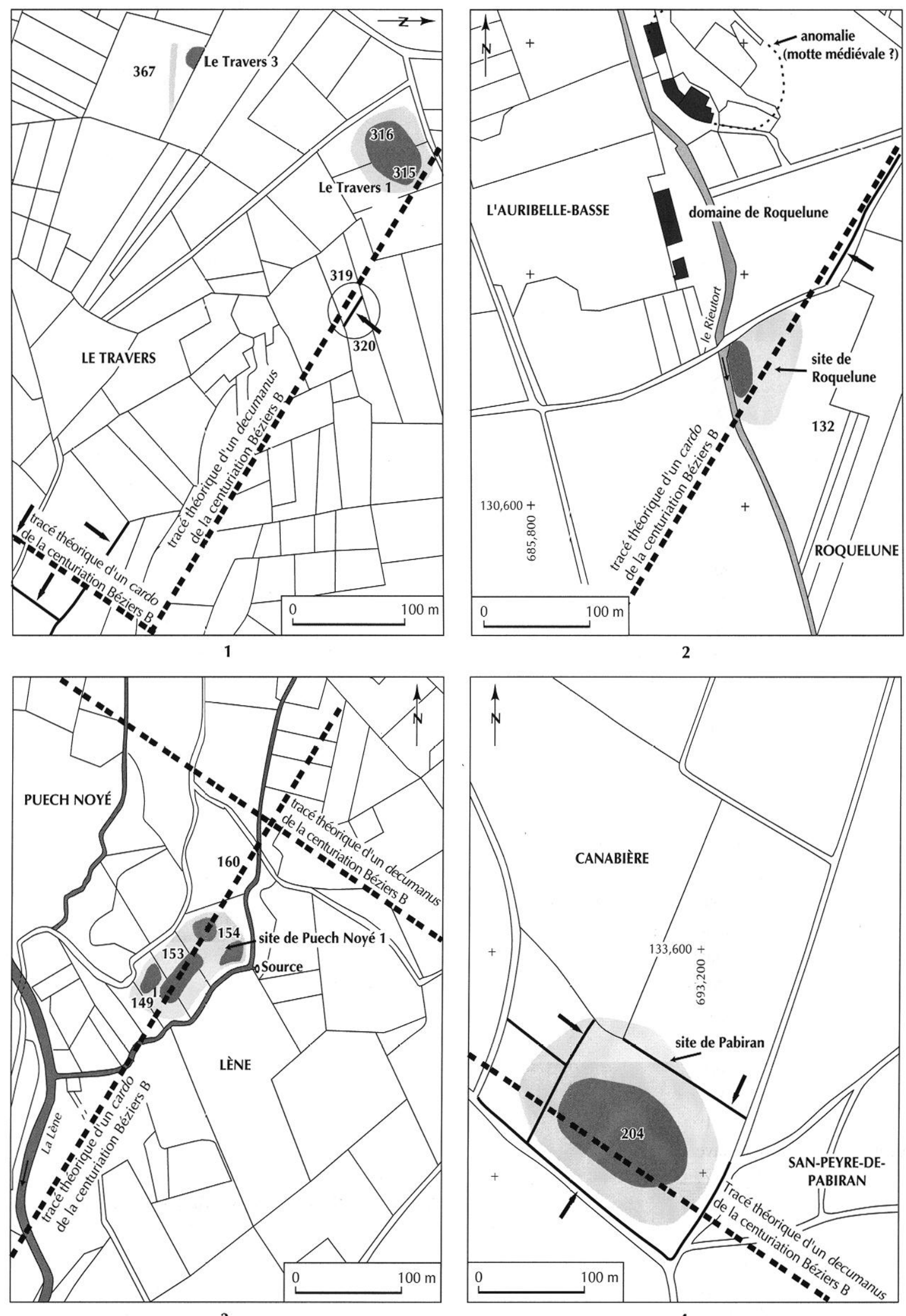

Fig. 4 - Établissements ruraux antiques fondés entre la fin du II s. et le milieu du $I^{\text {er }}$ s. avant J.-C. et installés sur ou contre un axe (cardo ou decumanus) de la centuriation Béziers B (Hérault) : 1, Alignan-du-Vent, Le Travers ; 2, Pézenas, Roquelune ; 3, Magalas, Puech Noyé 1 ; 4, Monlagnac, Pabiran (dessin S. Mauné). 


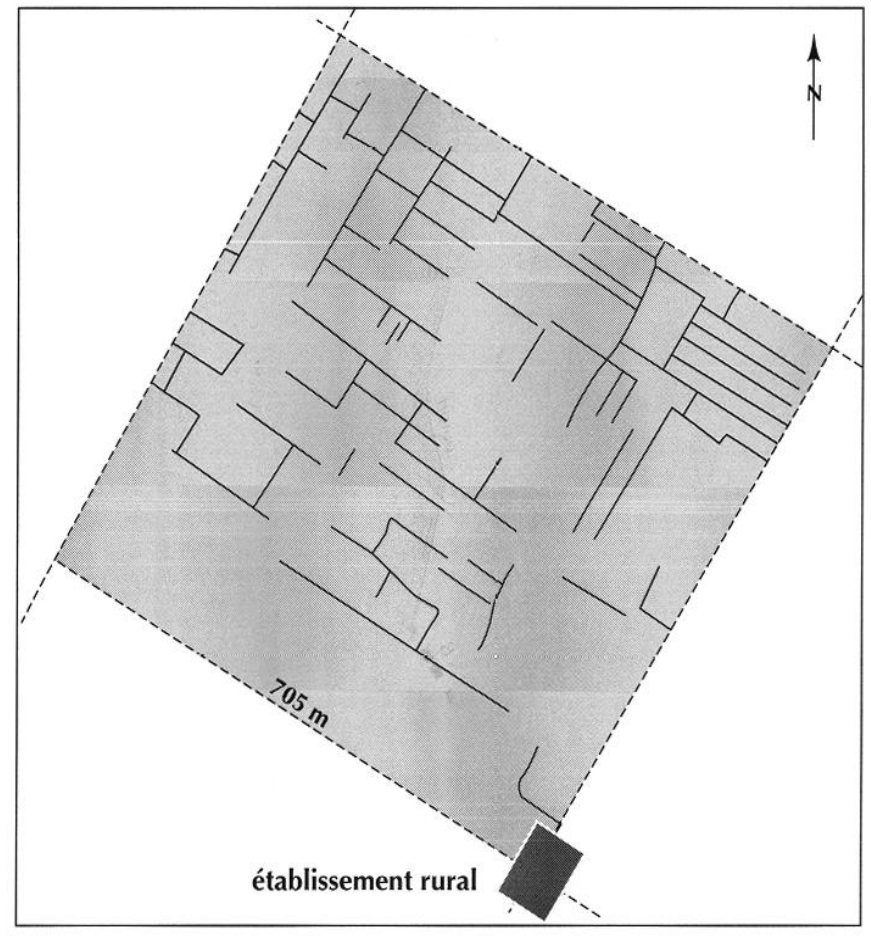

Fig. 5 - Un exemple d'établissement rural de la première moitié $d u$ ${ }^{\text {Ir }}$ s. avant J.-C. établi au croisement d'un decumanus et d'un cardo de la centuriation cadastre précoloniale Béziers B : Vareilles à Paulhan (Hérault). Le site est inclus dans un réseau dense de traces agraires (fossés, talus, chemins, limites de parcelles), isoclines à l'orientation de la centuriation $\left(N .32^{\circ} \mathrm{E}\right.$.) et présentes sur le fond cadastral communal du milieu du XIX' s. Échelle: $1 / 10000$.

observé dans la région de Béziers et plus particulièrement au nord de la ville (vallée du Libron) et en Biterrois nord-oriental, sur la rive gauche de l'Hérault et au sud de la rivière Dourbie qui marque la frontière avec le territoire lodévois. Dans ce secteur (fig. 3), plus de la moitié des 150 sites fondés entre la fin du II $\mathrm{s}$. et le milieu du ${ }^{\text {er }}$ s. avant J.-C. sont installés sur un axe théorique de ce système (fig. 4 et 5 ), très souvent au milieu de nombreuses limites parcellaires isoclines à N.32ํ․ (Dodinet, 1985 ; Mauné, 1993, 1995, 1996, 1998a, p. 45-56 ; Vidal et al., 1995). Les données concernant cette centuriation (Clavel-Lévêque, 1995a, 1995b) montrent - malgré quelques critiques (Chouquer, 1997; Favory, 1997) - que sa genèse est ancienne car elle peut être située entre la fin du II ${ }^{e} s$. et le milieu du I ${ }^{\text {er }}$ s. avant J.-C. On se trouve ici en présence d'une opération de limitation effectuée sans fondation coloniale puisque la Colonia Urbs Iulia Septimanorum Baeterrensis (Clavel, 1970, p. 161-167), implantée sur un oppidum indigène, ne sera créée par Octave qu'en 36-35 avant J.-C. (voir en dernier lieu: Christol, 1994, p. 54). L'objectif de cette limitation précoloniale aurait été d'organiser le vaste territoire compris entre les confins orientaux de la cité de Narbonne et les territoires arécomiques situés à l'est de l'étang de Thau et limité au nord par les contreforts du Massif central. Le semis d'exploitations rurales mis en évidence par les recherches archéologiques éclaire la réussite effective de cet outil de contrôle et d'aménagement du sol. Néanmoins, la répartition, en Biterrois, des traces parcellaires isoclines à cette centuriation laisse apparaître des vides qui permettent de nuancer l'idée d'une organisation systématique de ce territoire : à l'évidence, et tout en respectant une orientation et une forme préétablies, les concepteurs de ce système ont pris en compte un certain nombre de paramètres politiques et topographiques qui expliqueraient - à côté de phénomènes de recouvrement et d'effacement que l'on ne peut ignorer - le caractère discontinu de son emprise topographique. Que le Biterrois ait été totalement mesuré et borné est une chose ; qu'il ait fait l'objet d'une restructuration totale, par le biais de fossés, talus, chemins, etc. en est une autre. On doit d'ailleurs rappeler que $\mathrm{M}$. Dodinet avait montré, dans sa thèse de

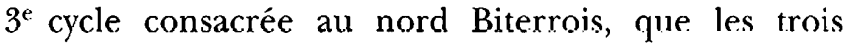
systèmes cadastraux successifs Béziers B, C et A se complétaient dans l'espace sans se superposer nettement et laissaient subsister des vides (Dodinet, 1985) ; observations débouchant sur l'idée d'une construction évolutive et diachronique du paysage dans laquelle les centuriations ne constituent finalement qu'un épisode parmi d'autres.

Cet important effort de structuration du territoire - qui dû nécessiter de longues années de travail et une importante main d'œuvre, sans doute militaire - était également à la hauteur de l'importance stratégique du Biterrois qu'il convient de ne pas sous-estimer : la vallée de l'Hérault est un axe de circulation très important (Cessero/Luteva/Condatomagus/Segodunum) entre le littoral et le sud du Massif central, où sont localisés les Rutènes (voir en dernier lieu : Barruol, 2000). De même, la vallée de l'Orb commande l'accès au secteur minier de Lascours et des monts d'Orb où l'existence d'une voire de plusieurs sociétés de publicains contrôlant l'exploitation minière dit assez l'importance économique de ces confins montagneux. Il convenait donc pour Rome de s'assurer la maitrise effective de ces microrégions en les 
pacifiant et en les romanisant, mais aussi en y établissant des alliances solides avec les entités politiques indigènes locales, rompues depuis longtemps aux contacts avec les Grecs et les Italiens en raison de la proximité d'Agde et de l'ancienneté des échanges commerciaux avec l'Italie. L'accession des agglomérations de Cessero, Piscenae et Luteva au statut d'oppidum latinum, sans doute à la période césarienne, constituerait selon toute vraisemblance l'aboutissement logique de cette politique d'intégration (Mauné, 1998a, p. 69-70; Christol, 1998, p. 211-212) et pourrait même rendre compte d'une phase d'alliance contemporaine de la conquête de la fin du II ${ }^{e}$ s. avant J.-C. Elle témoignerait en tout cas d'une volonté politique forte, visant à verrouiller la vallée de l'Hérault et les territoires situés à l'est de Narbonne.

Plus à l'ouest, d'autres secteurs ont pu également faire l'objet d'une cadastration précoce. Entre Narbonne et Toulouse, le cadastre Toulouse A - dont le module est le plus faible actuellement connu en Gaule - pourrait dater de la période tardo-républicaine. On connaît en effet, pour les Romains, l'importance militaire et commerciale de la capitale tectosage puisqu'un foedus avait été passé entre Toulouse et Rome, cette dernière installant sur place une garnison, jusqu'à la révolte de. 106 avant J.-C. (Labrousse, 1968, p. 128). La mise en place de cette centuriation pourrait donc être ultérieure à ces événements et sanctionnerait ce soulèvement. En effet, le fait que Crassus ait convoqué individuellement les vétérans de Toulouse et Narbonne ( $B G$, III, 20,2), au début de la guerre des Gaules, est très vraisemblablement la preuve d'assignations viritanes opérées sur l'ancien territoire de la cité indigène. Les bénéficiaires de ces assignations peuvent avoir été nombreux : vétérans et/ou auxiliaires de Marius et/ou de Pompée par exemple. Enfin, entre la rivière Agly et les Pyrénćcs, la région d'Elne/Ruscino - où nous l'avons vu, l'éclosion précoce d'un premier réseau d'établissements ruraux est nette a aussi pu faire l'objet d'un arpentage, mais il reste ici à démêler l'écheveau chronologique des différents systèmes présents dans cette plaine. Toutefois, J. Kotarba plaide prudemment pour un lien assez net entre cette génération de sites et la centuriation nord-sud (Kotarba, 1995, p. 551), Ruscino A, mise en évidence par les travaux de J. Soyer (1980).

Quoi qu'il en soit, il reste cependant à évoquer la difficile question du statut de ces terres de Transalpine occidentale ; si tout ce territoire relevait de l'ager publicus, dans le détail il est en effet certain que les situations juridiques ont pu être très variables. Le Narbonnais ne pose pas de problème puisqu'il a reçu un groupe de colons civils en 118 avant J.-C. (Gayraud, 1981, p. 149-160), mais il en va autrement du Biterrois, du Lodévois, de la région de Toulouse/Carcassonne et du Roussillon. Aucune inscription ni mention littéraire ne fait en effet directement allusion au statut de ces territoires pérégrins entourant Narbonne au nord, à l'ouest et au sud, pour la période qui nous occupe ici, mais peut-on sérieusement penser que Rome se désintéressa de la province au point de ne pas l'organiser méthodiquement? Même si l'ensemble des données matérielles et historiques disponibles pourrait appuyer l'hypothèse d'un ou plusieurs statuts intermédiaires ayant précédé la fondation coloniale de Béziers et la fondation latine de Carcassonne ${ }^{16}$, on ne peut, de toute manière, se satisfaire de ces quelques éléments et, dans l'attente d'hypothétiques trouvailles épigraphiques, on ne doit pas s'empêcher de proposer des idées et hypothèses. Mais, finalement, ce qui compte ici n'est pas tant la question du statut des terres et des territoires à proprement parler que celle des formes juridiques de leur exploitation: locatio, vente questorienne et occupatio (sur ces questions, voir Botteri, 1992 ; Moatti, 1992) qui ont pu être mises à profit par les Italiens pour s'établir sur l'ager publicus et s'y tailler des propriétés. Cette diversité des modes d'appropriation du sol, dont témoignent les textes un peu plus tardifs des agrimensores, rend compte de la complexité de la problématique du fait colonial et de la présence italienne en milieu rural ; d'autant qu'il s'agit ici de données presque impalpables (sauf découverte épigraphique) du point de vue archéologique. De même, on rappellera, en se fondant sur les mentions de Cicéron (voir supra), la variété des activités des Italiens présents dans la province qui induisent des adaptations certaines aux conditions naturelles et aux possibilités économiques locales. Assurément, ces deux concepts - diversité de l'appropriation du sol et pluralité des formes d'exploitation entretiennent d'étroites relations, ce qui permettra peut-

16. Pour Ruscino et Toulouse, il n'y a pas d'attestation de colonie. A. Chastagnol évoque le hasard des découvertes épigraphiques mais aussi le fait que ces cités aient pu rester des civitates seulement dotées du droit latin, sans le titre colonial (Chastagnol, 1997, p. 57). Pour Carcassonne, la colonie latine succède à un oppidum latinum mentionné par Pline. 
être prochainement et en se fondant sur des exemples concrets d'avancer dans cette problématique essentielle.

\section{EN TRANSALPINE OCCIDENTALE, UN PEUPLEMENT ITALIEN RURAL PRÉCOCE ?}

À ce niveau de l'exposé résumons les données qui viennent d'être présentées à propos de la Transalpine occidentale : partout où des enquêtes microrégionales ont été mises en place, on a observé l'existence d'un nombre important d'établissements ruraux antérieurs au milieu du I ${ }^{\text {er }}$ s. avant J.-C. Au moins un site sur dix peut être considéré comme préromain, les autres apparaissant entre la fin du $\mathrm{II}^{\mathrm{e}}$ s. et le milieu du I ${ }^{\mathrm{er}} \mathrm{s}$. avant J.-C. Autour de Narbonne, zone sur laquelle des enquêtes de terrain approfondies viennent de commencer, ce phénomène pourrait être mis en relation avec la déduction coloniale civile de 118 avant J.-C. Le dossier épigraphique, sur lequel nous aurons l'occasion de revenir, corrobore d'ailleurs cette hypothèse car c'est de la région de Narbonne et de son hinterland que proviennent un certain nombre de gentilices italiques très rares qui pourraient remonter à la période antérieure à la seconde dćduction du milicu du ${ }^{\mathrm{er}}$ s. avant J.-C. (Gayraud, 1981, p. 149-151 et p. 411-443 ; Christol, 1995c, p. 339). Dans la région de Béziers, et dans une moindre mesure en Roussillon, cette phase de peuplement semble pouvoir être mise en relation avec la présence d'une centuriation. En Biterrois, l'ampleur relative de ce mouvement pose la question de l'origine ethnique des occupants de ces établissements: les grands oppida (Ensérune, Aumes, Magalas/Montfo) restent en effet occupés après la conquête. Si l'on peut supposer qu'une bonne partie de ces sites a pu être occupée par des indigènes fixés par Kome sur des zones de fronts pionniers et ce pour diverses raisons, peut-on sérieusement réfuter l'hypothèse d'une présence diffuse d'Italiens dans les campagnes (colons viritim, possessores...) alors qu'à cette époque, la question des terres est, pour Rome, un enjeu capital dont rend bien compte l'épisode des Gracques, qui précède la conquête de 121-118 avant J.-C. (Nicolet, 1967 ; Moatti, 1993) ? Si à ce stade de l'exposé, on ne peut avoir, en l'absence de preuve irréfutable, aucune certitude quant à la validité de cette hypothèse, nous allons voir que d'autres données peuvent être mises à contribution pour avancer dans cette étude.

\section{L'APPORT ENCORE RESTREINT MAIS PROMETTEUR DES DONNÉES MATÉRIELLES}

Si les résultats des enquêtes microrégionales effectuées en Transalpine occidentale présentent une réelle homogénéité, il demeure cependant bien difficile, dans l'état actuel des recherches, de documenter matériellement cette présence italienne rurale précoce que l'on pressent pourtant bien. C'est, je crois, dans ce domaine que les efforts devront être les plus importants car les observations matérielles peuvent constituer des preuves indubitables. Il convient par exemple de souligner les différences pouvant exister entre les vaisseliers italiens et indigènes, notamment en ce qui concerne la préparation et la cuisson des aliments. Même si les ensembles de référence sont encore rares et qu'il existe des phénomènes d'acculturation difficiles à saisir, cette approche permettra sans doute de réels progrès. D'autres éléments peuvent également être pris en considération : les graffiti latins peuvent être décisifs pour montrer la présence d'un groupe italien; de tels documents ont par exemple été observés sur des céramiques du complexe minier de Lascours (voir infra). D'une manière beaucoup plus ponctuelle, la découverte inédite, faite par J. Kotarba sur l'établissement rural du Puig del Baja I en Roussillon (Kotarba, 1996), de fragments de tegulae présentant un dégraissant volcanique similaire à celui utilisé pour la confection des amphores Dressel 1 de Campanie constitue également un indice de poids en faveur d'une installation italienne précoce. D'autant que ces artefacts étaient associés à des fragments de béton de tuileau et que le mobilier céramique accompagnant ces éléments permet de proposer une datation autour des années 11070 avant J.-C. Encore balbutiante en Languedoc occidental, l'archéologie préventive rurale offrira peut-être, dans le cadre des travaux de l'autoroute A75 et du TGV, des opportunités d'observations architecturales et/ou technologiques décisives. Pour l'heure, on doit encore se contenter de données ponctuelles.

Ainsi, à Magalas, à une douzaine de kilomètres au nord de Béziers, sur un établissement rural (Saint-Jean, supra fig. 2) occupé à partir de la fin du $\mathrm{II}^{\mathrm{e}}$ s., la découverte d'un four ayant produit de la céramique à vernis noir d'excellente qualité attire notre attention sur la présence éventuelle d'artisans italiens venus s'installer à moins de $3 \mathrm{~km}$ de l'oppidum de Montfo/Magalas (Mauné, Sanchez, 1999). Le répertoire est essentiellement 
composé d'assiettes Lamb. 6/Lamb. 36, de coupes Lamb. 31 et Lamb. 27 ; les palmettes de très bonne qualité qui ornent plusieurs fonds de coupe constituent un bon argument en faveur d'une datation haute que l'on situera, dans l'état actuel des recherches, entre le dernier quart du II ${ }^{\mathrm{e}} \mathrm{s}$. et le deuxième quart du $\mathrm{I}^{\mathrm{er}} \mathrm{s}$. avant J.-C. La présence d'artisans italiens semble corroborée par le faciès particulier de cet atelier qui n'a produit que de la céramique à vernis noir et un peu de vaisselle à pâte claire, contrairement aux officines indigènes de la Lagaste (Rancoule, 1970) et de Bouriège (Séjalon, 1998) ${ }^{17}$ situées dans la vallée de l'Aude et dont l'éventail des productions est beaucoup plus large. De même, il n'est pas inintéressant de préciser que ce secteur artisanal est installé contre le tracé d'un decumanus de la centuriation Béziers B qui le sépare de la zone d'habitat. L'intérêt de cette découverte est donc multiple et fait écho à celle de l'atelier d'artisans siciliotes ayant fonctionné sur l'oppidum de Brignon (Gard) entre le premier quart et le milieu du Ir s. avant J.-C. Le fait que l'un soit installé en contexte " rural » et l'autre en contexte « urbain " serait-il alors révélateur des différences qui existent entre Transalpine occidentale et orientale ? La question mérite en tout cas d'être posée.

Compte tenu du faible nombre de sites ruraux fouillés de manière extensive en Languedoc-Roussillon, on peut considérer que les occasions de voir apparaitre des vestiges antérieurs au milieu du $\mathrm{I}^{\mathrm{er}} \mathrm{s}$. avant J.-C. sont encore faibles, ce qui explique la minceur du dossier matériel. Quand le corpus sera plus étoffé, il sera sans doute plus facile de réfléchir sur l'ensemble des caractères discriminants (architecture, matériaux de construction, faciès du vaisselier, petit mobilier, graffiti...) permettant de distinguer les sites occupés par des indigènes de ceux occupés par des Italiens. C'est certainement un objectif difficile mais doit-on et peut-on en faire l'économie ?

\section{L'IMPORTANCE DE L'EXPLOITATION MINIÈRE}

Dans cette problématique d'une présence italienne précoce en Transalpine occidentale, la question des mines semble être également fondamentale. En effet, et

17. Voir aussi P. Séjalon, Bouriège (Aude), Devant la Ville, notice de fouille de sauvetage urgent, Bilan scientifique de la région LanguedocRoussillon 1997, p. 32.

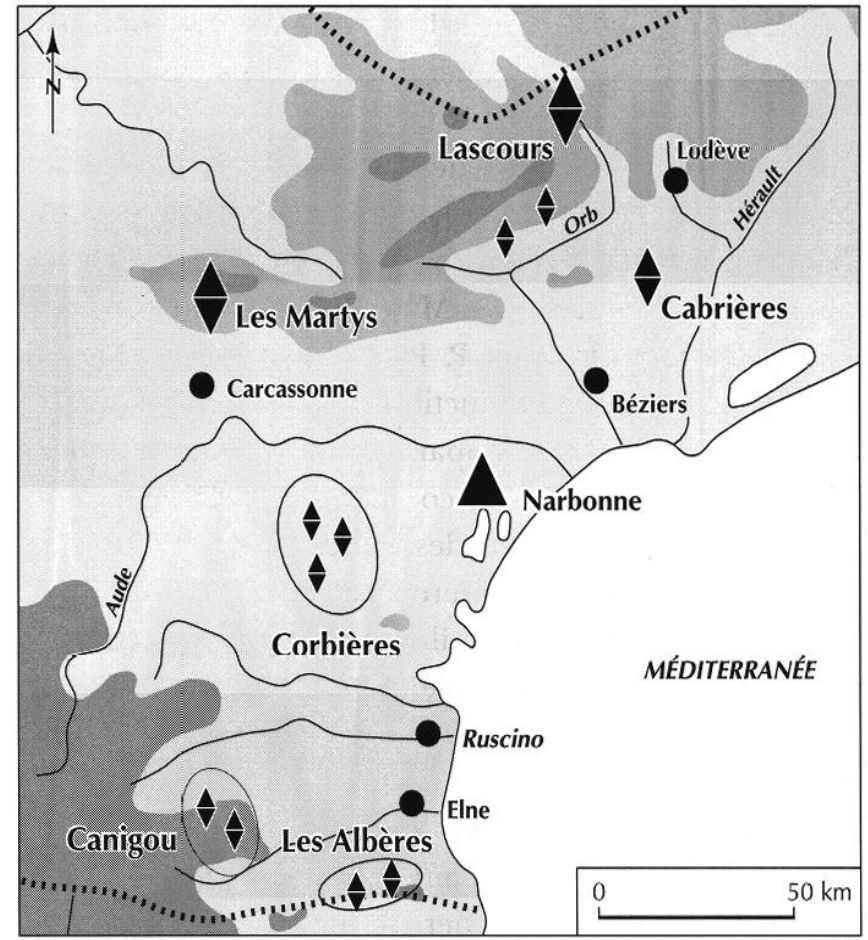

Fig. 6 - Les secteurs miniers tardo-républicains en Transalpine occidentale: grands losanges, secteurs miniers fouillés ; petits losanges, secteurs décelés en prospection.

même s'il est probable que les indigènes exploitaient les mines de fer, de cuivre et d'argent avant l'annexion romaine (Rancoule, 1994), les traces matérielles relatives aux activités minières et métallurgiques sont essentiellement à rattacher à la fin du $\mathrm{II}^{\mathrm{e}} \mathrm{s}$. et au $\mathrm{I}^{\mathrm{er}} \mathrm{s}$. avant $\mathrm{J}$.-C. Elles pourraient indiquer que des publicani - parfois regroupés en societates - se sont installés aux confins de la province, en zone de moyenne montagne (fig. 6), et y ont développé leurs activités jusque dans le courant du ${ }^{\mathrm{er}} \mathrm{s}$. après J.-C. Celles-ci étaient encadrées par l'État romain qui attribuait des concessions/locations (Domergue, 1994, p. 99) et il semble, encore une fois, qu'il faille attribuer à des Italiens installés en Espagne, comme M. Planius Heres, un rôle peut-être prépondérant dans ce processus (Domergue, 1965, p. 23 et en dernier lieu Deniaux, 1993, p. 339).

Les travaux de C. Domergue aux Martys (Aude), dans le secteur de la montagne Noire, ont ainsi révélé la présence d'une douzaine de bas fourneaux de réduction de minerai de fer ayant fonctionné vers le milieu du $\mathrm{I}^{\mathrm{er}} \mathrm{s}$. avant J.-C. (Domergue éd., 1993), mais des indices sérieux font penser à un démarrage de cette activité dès 
la première moitié de ce siècle ${ }^{18}$. De même, les prospections que M. Passelac a menées dans le Piémont occidental de ce massif ont permis la découverte de trois sites métallurgiques, certes modestes, mais qui ont été en activité aux II ${ }^{\mathrm{e}}$ et ${ }^{\text {er }}$ s. avant J.-C. (Passelac, 1998, p. 140). S'agit-il d'installations préromaines ou bien faut-il les rattacher au complexe des Martys ? Pour les Corbières, les prospections de B. et P. Pauc ont mis en évidence l'existence de sites de réduction de minerai de fer mais la grande majorité appartient au Haut-Empire. Néanmoins, les recherches conduites dans le secteur de Salsigne ont montré que des mines de cuivre avaient fonctionné durant la première moitié du $\mathrm{I}^{\mathrm{er}} \mathrm{s}$. avant J.-C. (Guilbaud, Landes, 1977) ; il est donc possible que des filons ferrugineux aient également été exploités à cette époque dans les Corbières (voir en dernier lieu : Pauc, Pauc, 1998).

Dans les Pyrénées, une exploitation précoce des mines de fer du massif du Canigou a été reconnue (Rico, 1997, p. 258-262) et les recherches de J. Kotarba dans les Albères et dans le Canigou ont également montré l'existence de ferriers d'époque tardo-républicaine (Kotarba, 1995 , p. 550 et aimable rens. de l'auteur). Beaucoup plus à l'ouest, aux confins de la province, dans la vallée de l'Arizc (Ncscus, Ariège), l'exploitation de mines de cuivre et d'argent paraît également effective durant cette période (Dubois, 1992). D'une manière générale, ces exploitations sont mises en évidence grâce à la présence abondante d'amphores vinaires Dressel la dont A. Tchernia avait déjà noté la densité sur les secteurs miniers de Gaule méridionale (Tchernia, 1986, p. 92-93).

En Biterrois, dans le bassin cuprifère de Cabrières (Hérault), l'exploitation des mines de cuivre semble reprendre durant la première moitié du Ir $\mathrm{s}$. avant J.-C., voire avant (Ambert et al., 1985 et pour un résumé, Mauné, 1998a, p. 230-234). La mine de Pioch Farrus IV a ainsi livré plusieurs lampes à huile Dressel 4, du « type aux oiseaux ", datables de la fin de la période tardorépublicaine et deux graffiti nominatifs - Gaius et Aur(elianus) ou Aur(elius) - peut-être contemporains;

18. C. Domergue, Les Martys (Aude), Montrouch-Domaine des Forges, Bilan scientifique de la région Languedoc-Roussillon 1995, p. 34-35. Voir notamment les résultats des fouilles du fourneau 106 datant « au moins du milieu du I Ir s. avant J.-C. " et qui est postérieur aux fourneaux 101, 102,103 et 104. enfin, de récentes datations au ${ }^{14} \mathrm{C}$ ont confirmé cette chronologie ${ }^{19}$. On mettra ces observations en parallèle avec la présence de deux villages de plaine installés à moins de $5 \mathrm{~km}$ plus à l'est; il est probable que ces habitats groupés, peu structurés, accueillaient les mineurs et constituaient le ou les centres névralgiques de ces exploitations. Enfin, la composition hétérogène de certains filons laisse également supposer que l'on tirait un peu d'argent de ces mines (Mauné, 1998a).

Mais les données les plus sûres proviennent, dans l'état actuel des recherches, du secteur minier de la haute vallée de l'Orb où les travaux de R. Gourdiole et C. Landes prouvent l'installation d'Italiens avant le milieu du I ${ }^{\text {er }}$ s. avant J.-C. (en dernier lieu Gourdiole et al., 1998 ; Gourdiole, Landes, 1998, 2000). La présence d'une exploitation romaine tardo-républicaine antérieure au milieu du ${ }^{\text {er }}$ s. avant J.-C. a été mise en évidence grâce à la découverte d'une trentaine de tessères en plomb d'environ 2 à $3 \mathrm{~cm}$ de diamètre, souvent épigraphes et figurées sur les deux faces. Ces éléments peuvent présenter plusieurs légendes différentes - SS, développé en $S$ (ocietas)s(?) ; SR en S(ocietas) R(utenorum); $S O C A R C$ en S(ocietas) arg(entariarum) et ROT en Rot(enorum) - qui renvoient à l'existence d'une ou de plusieurs entreprises privées (societates). Cés éléments fournissent aussi des informations sur l'aire d'activité de cette ou de ces sociétés grâce à des inscriptions figurant au droit et au revers: Arg(ento fodinae) Rot(enorum) Rot(enorum); soc(ietas) arg(ento fodinarum) Rot(enorum); s(ocietas) R(utenorum) et (Ar)gento fo(dinae) in Ruta(enis). Le lieu de découverte (alt. $580 \mathrm{~m}$ ), très enclavé dans la haute vallée de l'Orb, sur le flanc nord du mont Faulat (alt. $807 \mathrm{~m}$ ), correspond à une agglomération minière sur laquelle C. Landes, R. Gourdiole et leur équipe ont pu effectuer une fouille extensive couvrant environ $1700 \mathrm{~m}^{2}$. La découverte de meules de type pompéien originaires d'Orvieto en Italie (Domergue et al., 1997, p. 53-54), d'un chapiteau probablement toscan, le faciès

19. Ces datations ont été effectuées dans le cadre des recherches dirigées par P. Ambert, N. Houlès et L. Carozza (EHESS/CNRS-UMR 150) sur la mine de Pioch Farrus IV. La première analyse AMS 14 a été réalisée sur un fragment de bois prélevé sur la poutre principale d'un barrage souterrain constitué d'argile palissadé (planches et pieux) et a livré une datation $2050 \pm 60 \mathrm{BP}$; la seconde a été faite sur le manche d'une herminette/hache-marteau de type ascia et a donné la datation $2100 \pm 50$ BP (rf. P. Ambert, Cahrières, Hérault, Pioch Farrus IV, Bilan scientifique de la région Languedoc-Roussillon 1997, p. 76-77). 
céramique, l'utilisation de tegulae pour les toitures - dont une cinquantaine portent l'estampille $S O C$ - et la mise au jour de l'ensemble thermal le plus ancien de Transalpine (type Bouet 5a) confirment la présence d'un groupe plus ou moins important d'Italiens installés ici dès la première moitié du I ${ }^{e r}$ s. avant J.-C. D'autres mines ont également fait l'objet d'une exploitation précoce autour du mont Faulat, comme par exemple celle de Bournac dont un dépotoir a notamment livré trois graffiti latins inscrits sur de la céramique non tournée à panse peignée (Gourdiole et al., 1998, p. 22-23), de la campanienne $\mathrm{A}$ et $\mathrm{B}$, des dérivées de campanienne $\mathrm{C}$ probablement régionales, de la céramique commune italique et des amphorcs Drcsscl la.

La présence d'un groupe de population italienne dans la haute vallée de l'Orb, à plus de $70 \mathrm{~km}$ au nord de Béziers et à plus de $100 \mathrm{~km}$ de Narbonne, au contact des territoires rutènes, constitue finalement l'élément le plus probant à l'appui de notre hypothèse. Si une telle installation fut possible - d'autant qu'il ne s'agit pas d'une exploitation ponctuelle mais de la création d'une petite agglomération isolée comportant des éléments de la vie à l'italienne ( $c$. supra) - y avait-il réellement du danger à s'installer dans les plaines biterroises et roussillonnaises, dans la moyenne vallée de l'Aude et en Lauragais/ Toulousain pour y fonder des exploitations rurales ? Et l'on doit à nouveau discuter du cas emblématique du mausolée italien d'Argenton/ Le Fugeret qui pourrait, pour la Provence, faire écho aux découvertes de Lascours (Bérard, Roth Congès, 1997). La situation topographique est en effet ici encore plus difficile que dans la haute vallée de l'Orb puisque ce monument a été construit à $1300 \mathrm{~m}$ d'altitude. Alors, si bien sûr on peut remettre en cause l'hypothèse - certes encore fragile - d'une exploitation minière tardo-républicaine sud-alpine, il n'empêche que la mise en perspective de ces deux dossiers fait pressentir un phénomène très précoce d'exploitation économique intensive des secteurs les plus reculés de la Province. On imagine mal en tout cas que ces centres, établis aux confins de la Transalpine, aient été totalement isolés, à la merci des tribus indigènes locales et que ces dernières aient $\mathrm{pu}$ - du moins pour la partie méridionale du Massif central - constituer une menace sérieuse à l'encontre des sociétés de Publicains et des Italiens établis sur ces zones.

\section{LA COHÉRENCE DU DOSSIER ÉPIGRAPHIQUE}

Les données épigraphiques - malheureusement encore rares pour cette haute époque - témoignent également de la spécificité de la zone Narbonne/Béziers et sont donc particulièrement précieuses. On ne retiendra ici que l'exemple emblématique de l'épitaphe trouvée à Villemagne-l'Argentière, dans la vallée de la Mare, affluent de l'Orb situé à environ $20 \mathrm{~km}$ en aval de Lascours, ce qui renforce encore son intérêt. Cette inscription mentionne en effet l'appartenance d'un personnage à la tribu Pollia, où étaient enregistrés les premiers colons de Narbonne, et M. Christol propose de la dater entre l'époque de Sylla et la fin de la République mais admet que l'on peut difficilement placer un tel document au-delà de la période césarienne (Bellan, Christol, 1986; Christol, 1995a, p. 55). On peut donc considérer, à juste titre, que cette inscription rend compte de la présence d'un citoyen romain venu s'installer ou fonder un domaine sur les marges du territoire de la cité de Narbonne. L'apport d'un tel document est capital car il permet de s'interroger encore une fois sur les spécificités régionales du fait colonial tardo-républicain et pourrait être révélateur d'un vaste phénomène de colonisation que l'on pressent bien pour les secteurs de plaine et qui s'étendrait même aux zones de confins. Assurément, le corpus des inscriptions latines de haute époque devra être augmenté mais d'ores et déjà on sait que ce type de document existe, ce qui permet d'être optimiste. Quoi qu'il en soit, ce dossier de Villemagnel'Argentière et l'analyse de l'ensemble de la documentation épigraphique de la zone Béziers/ Narbonne ont conduit $\mathrm{M}$. Christol à rejeter une histoire épigraphique de la Transalpine décrite comme une succession de phases généralisées à l'ensemble de l'aire provinciale et à reconsidérer l'importance précoce de cette partie de la province, "fortement imprégnée d'influences italiennes parce que réceptacle d'immigrants " dont les textes anciens montrent l'importance pour le premier tiers du I ${ }^{\text {er }}$ s. avant J.-C. (Christol, 1995a, 1995b, 1995c, p. 341).

$$
\begin{aligned}
& * \\
& * *
\end{aligned}
$$

Ce premier bilan de la question des premières installations italiennes en Gaule méridionale a été l'occasion de montrer toutes les différences qui peuvent exister entre la Transalpine orientale et occidentale. Dans les 
deux cas, on observe un certain parti pris qui traduit, peut-être plus que les réalités antiques, l'importance et le poids du legs historiographique mais également les sensibilités personnelles des uns et des autres. Quoi qu'il en soit, des efforts importants devront être consentis en ce qui concerne les éléments discriminants permettant de distinguer les groupes indigènes et italiens. Nous les avons brièvement évoqués, et il nous semble qu'il faut aussi insister sur les pratiques funéraires : espace anthropologique propice à l'expression de gestes intimes, mais aussi de pratiques sociales, la mort constitue en effet un champ d'observation idéal pour analyser l'identité culturelle d'une population et ses modes d'expression (Bel, Feugère, 1998). De même, il semblerait opportun de progresser dans l'affinement des datations car on ne saurait se satisfaire de propositions chronologiques trop imprécises pour une période riche en événements politiques et militaires déterminants. À cet égard, les recherches que mène $\mathrm{C}$. Sanchez à Narbonne paraissent d'une importance capitale car nous disposons ici, avec la date de 118, d'un terminus chronologique aussi important que ceux de Carthage ou de Numance.

En attendant, les différences sont assez nettes entre Transalpine orientale et occidentale pour paraitre significatives, même si des nuances peuvent être apportées ici et là. On rappellera à cet égard les questions encore irrésolues soulevées par le mausolée d'Argenton/Le Fugeret (Alpes-de-Haute-Provence) et l'hypothèse de localisation de l'un des domaines du Quinctius de Cicéron dans la vallée de la Durance. À l'est du fleuve Hérault, la dispersion de l'habitat est mise en relation avec la romanisation progressive des campagnes. Elle correspondrait à l'éclatement des habitats groupés/perchés indigènes et aux nouvelles conditions socio-économiques. En Languedoc oriental, dans la vallée du Rhône et dans les Alpilles, Marseille serait l'initiatrice de ce mouvement, selon des modalités qui restent encore à définir ; Rome laissant à sa vieille alliée la jouissance de ces vastes territoires jusqu'à l'épisode malheureux de 49 avant J.-C. La présence italienne en milieu rural ne serait effective qu'à partir du milieu du I ${ }^{\text {er }}$ s. avant J.-C., période à partir de laquelle Rome aurait repris l'initiative en installant des colonies de vétérans à Arles, Vienne, Orange, puis Fréjus. L'essor quantitatif de l'habitat rural et les caractéristiques matérielles de certaines implantations seraient révélatrices de ce phénomène, mais des incertitudes chronologiques pèsent lourdement sur cette hypothèse.
À l'ouest de la vallée de l'Hérault, la situation est bien différente: l'existence d'un habitat indigène dispersé antérieur à la conquête semble établie, au moins en Minervois, dans la vallée de l'Aude et dans la région de Béziers. Partout, la multiplication du nombre des établissements ruraux à partir de la fin du $\mathrm{II}^{\mathrm{e}}$ s. est également très nette. À Narbonne, Rome fonde la première colonie romaine hors d'Italie et la peuple de civils, ce qui sous-entend peut-être que les problèmes de pacification étaient, sinon inexistants, du moins peu importants. Ailleurs, peut-on seulement expliquer cet essor par une explosion démographique du monde indigène, alors même que les habitats groupés préromains, perchés ou pas, restent occupés? Du reste, l'intérêt précoce et soutenu de Rome pour cette région est bien perceptible, et la présence italienne hors du Narbonnais pourrait être plus importante qu'il n'y paraît: les données relatives aux centuriations précoces, le dossier épigraphique, certes mince, quelques indices matériels et surtout l'exploitation des mines d'argent de la haute vallée de l'Orb mais aussi d'autres secteurs miniers (montagne Noire, Corbières, massif du Canigou, bassin de Cabrières) sont autant d'éléments qu'il faut verser à l'appui de l'hypothèse d'une vague d'immigration italienne ancienne et importante. C'est finalement le croisement et la confrontation de l'ensemble des informations disponibles qui éclairent cette question de la présence italienne précoce en Gaule transalpine et font apparaître de nettes divergences entre les deux parties de la Province. Il reste maintenant à s'interroger plus spécifiquement sur les questions d'ordre juridique et institutionnel que posent ces hypothèses et acquis récents - le ou les statuts tardo-républicains des agglomérations telles Béziers, Toulouse ou Carcassonne ne nous sont pas connus sans même évoquer ici le problème du contenu et de la date de la lex provincia - et l'on pressent bien l'intérêt d'un débat d'idées entre historiens et archéologues.

\section{Remerciements}

Il nous est très agréable de remercier ici P. Arcelin, M. Christol et M. Clavel-Lévêque qui ont assuré une relecture critique de ce manuscrit avant sa présentation au comité de lecture de Gallia. 


\section{BIBLIOGRAPHIE}

Ambert P., Barges H., Landes C.

1985 : Les mines de cuivre de PiochFarrus (Cabrières, Hérault). Préhistoire et Antiquité, in: Études languedociennes, Actes du $110^{\mathrm{e}}$ congrès national des sociétés savantes, Montpellier, 1985, Paris, Comité des travaux historiques et scientifiques, p. $97-113$.

ANDREAU J.

1987 : Ia vie financiere dans le monde romain. Les métiers des manieurs d'argent (IV siècle av. J.-C.-IIr siècle ap. J.-C.), Rome, Bibliothèques des Écoles françaises d'Athènes et de Rome, 265, $800 \mathrm{p}$.

\section{ARCELIN P.}

1999 : Entre Salyens, Cavares et Volques : peuplement protohistorique et dynamique culturelle dans la région Alpilles-Montagnette, in: Gateau F., Gazenbeek M. (éds), Les Alpilles et la Montagnette, Carte archéologique de la Gaule, 13/2, Paris, Fondation Maison des sciences de l'homme, p. 61-78.

\section{ARCHÉOMEDES}

1998 : Des oppida aux métropoles. Archéologues et géographes en vallée du Rhône, Paris, éd. Anthropos.

BADAN O., BRUN J.-P., CONGÈs G.

1995 : Les bergeries romaines de la Crau d'Arles, les origines de la transhumance en Provence, Gallia, 52, p. $263-310$.

1997 : Une auberge en Crau au I ${ }^{\text {er }} s$. av. J.-C. ?, in: Crau, Alpilles, Camargue: histoire et archéologie, Actes du colloque d'Arles, 18-19 nov. 1995, Arles, éd. du Groupe archéologique arlésien, p. $45-50$.

BALTY J.-C.

1981 : Un portrait romain d'époque républicaine trouvé en Narbonnaise à Murviel-lès-Montpellier (Hérault), Revue archéologique de Narbonnaise, 14, p. $89-98$.
1986 : Le portrait de Puissalicon, Bulletin de la classe des Beaux-Arts, Bruxelles, $5^{\mathrm{e}}$ série, 68, 1986-12.

\section{BARRUOL G.}

1969 : Les peuples préromains du sud-est de la Gaule, étude de géographie historique, suppl. 1 à la Revue archéologique de Narbonnaise, Paris, éd. De Boccard, $408 \mathrm{p}$.

2000 : Les peuples préromains du sud du Massif central d'après les sources écrites, in: Actes du XXI colloque international de l'Association française pour l'étude de l'âge du Fer; ConquesMontrozier, 8-11 mai 1997, Monographies d'archéologie méditerranéenne, 6, p. 7-18.

BATS $M$.

1986 : Le vin italien en Gaule aux II II $^{\mathrm{e}}{ }^{\mathrm{er}} \mathrm{s}$. av. J.-C. : problèmes de chronologie et de distribution, Dialogues dihistoire ancienne, 12, p. 391-430.

Bats M., Bertucchi G., Congès G., TREZINY $\mathrm{H}$.

1992 : Marseille grecque et la Gaule, Actes du colloque international d'histoire et d'archéologie et du $V^{c}$ congrès archéologique de Gaule méridionale, Marseille, 18-23 nov. 1990, Études massaliètes, 3 .

\section{BEL V., FEUGÈRE M.}

1998 : Les pratiques funéraires $\left(\mathrm{II}^{\mathrm{e}}-\mathrm{I}^{\mathrm{er}} \mathrm{s}\right.$. av. J.-C.), in : Fcugc̀rc M., Passclac M., Pellecuer C., Garmy P. (dir.), Signes de la romanisation, Revue archéologique de Narbonnaise, 31, p. 349-353.

Bellan G., Christol M.

1986 : Une inscription romaine à Villemagne-l'Argentière: le site de Saint-Martin-le-Vieux, Bulletin de la société archéologique et historique des Hauts Cantons de l'Hérault, 9, p. 33-44.

BELLET M.-E.

1990 : L'occupation de la moyenne vallée du
Calavon du Néolithique à la fin de l'Antiquité, Avignon, service d'archéologie du Vaucluse, $72 \mathrm{p}$.

Bellet M.-E., Borgard P., Carru D., Devalque C., leyraud J.-C., MEFFRE J.-C.

1994 : Habitat et cadastre B dans la région nord d'Orange: premiers résultats, in: Favory F., Fiches J.-L. (dir.), Les campagnes de la France médilerranéenne dans l'Antiquité et le haut Moyen Âge : études microrégionales, Documents d'archéologie française, 42, Paris, éd. de la Maison des sciences de l'homme, p. 134-140.

BÉrard G., Roth Congès A.

1997 : Notice du mausolée d'Argenton (Le Fugeret), in: Bérard G. (éd.), Les Alpes-de-Haute-Provence, Carte archéologique de la Gaule, 04, Paris, Fondation Maison des sciences de l'homme, p. 207-209.

BÉRATO J.

1994 : Taradeau, Tout-Egau (Bouches-duRhône), in: Pellecuer C. (éd.), Formes de l'habitat rural en Gaule Narbonnaise, t. 2, Juan-les-Pins, éd. APDCA.

1996a : Les Arcs-sur-Argens, Les Laurons/Saint-Pierre (Var), in: Pellecuer C. (éd.), Formes de l'habitat rural en Gaule Narbonnaise, t. 3, Juanles-Pins, éd. APDCA.

1996b : La petite paysannerie dans le Var à la fin de l'Âge du Fer et à l'époque romaine. Données archéologiques récentes, Annales de la société des sciences naturelles et d'archéologie de Toulon et du Var, 48, p. 197-207.

Bérato J., Borréani M., GÉbara C., MICHEL J.-M.

1995 : L'Âge du Fer dans la dépression permienne et dans les massifs des Maures et de l'Estérel (Var), Documents d'archéologie méridionale, 18 , p. $45-77$. 
Berger J.-F., Brochier J.-L., Jung C., ODIOT T.

1997 : Données paléogéographiques et données archéologiques dans le cadre de l'opération de sauvetage archéologique du TGV-Méditerranée, in: La dynamique des paysages protohistoriques, antiques, médiévaux et modernes, Actes des XVII rencontres internationales d'archéologie et d'histoire d'Antibes, Sophia Antipolis, 19-21 oct. 1996, Juan-lesPins, éd. APDCA, p. 155-184.

\section{BFRMOND I.}

1992 : Analyse spatiale des occupations du sol du passé. Approche mèthodologique et exemples à échelles différentielles, mém. de Maîtrise de Géographie, univ. Paul-Valéry/Montpellier III, oct. 1992, inédit.

Bermond I., Lugand M., Pellecuer C.

1989 : Le site de Mas Lavit, commune de Mèze (Hérault). Essai de prospection systématique d'un habitat antique et médiéval, Archéologie en Languedoc, 2-3, p. 43-57.

Bermond I., Pellecler C.

1997 : Recherches sur l'occupation du sol dans la région de l'étang de Thau (Hérault) : apport à l'étude des villae et des campagnes de Narbonnaise, Revue archéologique de Narbonnaise, 30, p. 63-84.

1998 : La villa et le domaine dans la région de l'étang de Thau de l'époque républicaine à la période du Haut-Empire (Hérault, France), in: Cité el lerritoire, Actes du 2 e colloque européen de Béziers, 24-26 oct. 1997, Paris, Presses universitaires franccomtoises, p. 55-66.

BERTUCCHI G.

1992 : Les amphores et le vin de Marseille. $V I^{e}$ s. avant J.-C.-II s. après J.-C., suppl. 25 à la Revue archéologique de Narbonnaise, 250 p.

BORRÉANI M., BRUN J.-P.

1990 : Une exploitation agricole antique à Costebelle (Hyères, Var) : huilerie et nécropole ( $\mathrm{I}^{\text {er }}$ s. av. J.-C.-VI ${ }^{\mathrm{c}}$ s. apr.
J.-C.), Revue archéologique de Narbonnaise, 23, p. 117-146.

1998 : La villa romaine des Mesclans à la Crau et son moulin hydraulique, in: Hommage à Pascal Lecacheur, textes réunis et édités par J.-P. Brun, Travaux du Centre archéologique du Var 1996-1997, p. 201-255.

\section{BOTTERI P.}

1992 : La définition de l'ager occupatorius, Cahiers du Centre G. Glotz, III, p. 45-55.

BRUN J.-P.

1989 : La villa gallo-romaine de SaintMichel à La Garde (Var). Un domaine oléicole au Haut-Empire, Gallia, 46, p. 103-162.

1996a : La villa romaine des "Platanes». Les origines de Saint-Tropez, Toulon, publication du Centre archéologique du Var, $91 \mathrm{p}$.

1996b: La grande transhumance à l'époque romaine. À propos des recherches sur la Crau d'Arles, Anthropozoologica, 24, p. 31-38.

BRUN J.-P. AVEC LA COLLAB. DE BORRÉANI M. 1999 : Le Var, Carte archéologique de la Gaule, 83/1, Paris, Fondation Maison des sciences de l'homme, $488 \mathrm{p}$.

Brun J.-P., Congès G., Gébara C., PasQualini M.

1985 : L'habitat rural dans le Var à l'époque romaine, Provence historique, 141 , p. 233-251.

BRUN J.-P., CONGÈS G., Pasqualini M. (DIR.)

1993 : Les fouilles de Taradeau. Le Fort, l'Ormeau et Tout-Egau, suppl. 28 à la Revue archéologique de Narbonnaise, 283 p.

BUCHSENSCHUTZ O.

1997 : Réflexion sur les parcellaires de l'Âge du Fer en France septentrionale, in: La dynamique des paysages protohistoriques, antiques, médiévaux et modernes, Actes des XVI ${ }^{\mathrm{e}}$ rencontres internationales d'archéologie et d'histoire d'Antibes, Sophia Antipolis, 19-21 oct. 1996, Juan-lesPins, éd. APDCA, p. 13-21.
Cameron F., Gébara C.

1994 : Fréjus : de la carte archéologique au modèle de peuplement suburbain, in: Favory F., Fiches J.-L. (dir.) : Les campagnes de la France méditerranéenne. dans l'Antiquité et le haut Moyen Âge: études microrégionales, Documents d'archéologie française, 42, Paris, éd. de la Maison des sciences de l'homme, p. 288-294.

Chastagnol A.

1997 : Les cités de la Gaule Narbonnaise. Les statuts, in: Actes $d u X^{p}$ congrès international d'épigraphie grecque et latine, Nîmes, 4-9 oct. 1992, Paris, Publications de la Sorbonne, p. 51-73.

Chovquer G.

1993 : Répertoire topo-bibliographique des centuriations de Narbonnaise, Revue archéologique de Narbonnaise, 26, p. 87-98.

1997 : Enquête sur la genèse des paysages : histoire et archéologie, une collaboration difficile, Les Nouvelles de l'archéologie, 69, p. 39-44.

\section{Christol M.}

1987 : Les Volques arécomiques entre Marius, Pompée et César, Mélanges Colbert de Beaulieu, Paris, éd. le Léopard d'Or, p. 211-219.

1992 : Composition, évolution et renouvellement d'une classe dirigeante locale : l'exemple de la cité de Nîmes, in: Frezouls E. (éd.), La mobilité sociale dans le monde romain, Actes du colloque de Strasbourg, nov. 1988, Strasbourg, p. 187-202.

1994 : Pline l'ancien et la formula de la province de Narbonnaise, in: La mémoire perdue. À la recherche des archives oubliées, publiques et privées, de la Rome ancienne, Paris, éd. De Boccard, p. 45-63.

1995a: De l'Italie à la Gaule méridionale : transferts d'influences, d'après les inscriptions de la fin du $\mathrm{I}^{\text {er }}$ s. av. J.-C. et du I ${ }^{\text {er }}$ s. ap. J.-C., in: Roma y el nacimiento de la cultura epigrafica en Occidente, Saragosse, Institut Fernando Le Catholique, p. 49-56.

1995b : De l'Italie à la Gaule méridionale, un transfert: l'épigraphie latine, 
Cahiers du Centre G. Glotz, VI, p. 163-181.

$1995 \mathrm{c}$ : Épigraphie et territoire autour de Narbonne et de Béziers, à propos d'une inscription d'Aigues-Vives, Hérault, Gallia, 52, p. 333-341.

1998 : Cités et territoires autour de Béziers à l'époque romaine, in: Cité et territoire, Actes du $2^{\mathrm{e}}$ colloque européen de Béziers, 24-26 oct. 1997, Paris, Presses universitaires franccomtoises, p. 209-222.

À paraître : Un pagus dans l'arrière-pays de Narbonne (CIL XII, 5390), in: Mélanges offerts à $L$. Gasperini (a cura di Gianfranco Paci).

Christol M., Fedière G.

1999 : La présence italienne dans l'arrière-pays de Narbonne : le dossier des Usuleni. Épigraphie de l'instrumentum domesticum et épigraphie lapidaire, in: Dialogues d'histoire ancienne, 25/1, p. 81-100.

Christoi. M., Goudineau C.

1988 : Nimes et les Volques arécomiques au $I^{\text {er }}$ s. avant J.-C., Gallia, 45, p. $87-103$.

Christol M., Plana-Mallart R.

1997 : Els negotiatores de Narbona i el vi català, Faventia, 19-2, p. 75-95.

1998 : De la catalogne à Narbonne: épigraphie amphorique et épigraphie lapidaire. Les affaires de Veiento, in: Epigrafia romana in area adriatica, Actes de la IX ${ }^{\mathrm{e}}$ rencontre francoitalienne sur l'épigraphie du monde romain, Macerata, 10-11 nov. 1995, Macerata, p. 273-302.

\section{Clavel M}

1970 : Béziers et son territoire dans l'Antiquité, Annales littéraires de l'université de Besançon, 112, Paris, éd. Les Belles Lettres, 664 p.

\section{ClAVEL-LÉVÊQUE M.}

1984 : Développement, cadastres et viticulture. Les terroirs du Biterrois, in : La vigne et la civilisation du vin en pays languedocien et catalan, Actes du colloque de Montpellier, 1984, p. 9-22.

1988 : Résistance, révoltes et cadastres : problèmes du contrôle de la terre en Gaule Transalpine, in: Forms of control and subordination in Antiquity, Actes du colloque de Tokyo, 1988, p. 177-208.

1990 : L'implantation des cadastres romains en Gaule méridionale et l'évolution des rapports gouvernants/gouvernés, in: Gouvernants et gouvernés dans l'Imperivm Romanvm (III s. av. J.-C.-Ires. ap. J.-C.), Actes du colloque, 28-31 mai 1989, univ. Laval (Canada), Cahiers des études anciennes, Montréal, XXVI, p. 73-91.

1995a : Béziers : territoire et cité. La fonction génétique du cadastre précolonial, in: Cité et territoire, Actes du colloque européen de Béziers, 14-16 oct. 1994, Paris, Annales littéraires de l'univ. de Besançon, p. 89-100.

1995b : Atlas des cadastres de Gaule -1- Le réseau centurié Béziers $B$, Paris, Annales littéraires de l'univ. de Besançon.

COMPS J.-P., KOTARBA J.

1997 : La campagne proche de Ruscino. Vie d'un terroir durant l'époque romaine, Études roussillonnaises, XV, p. 83-101.

D'Anna A., Leveau P., Mocci F.

1992 : La montagne Sainte-Victoire de la Préhistoire à la fin de l'Antiquité : les rythmes de l'occupation humaine (prospection-inventaire 1989-1992), Revue archéologique de Narbonnaise, 25, p. 265-299.

Dedet B., Michelozzi A., Py M., Raynaud C., Tendille C.

1978 : Ugernum, Protohistoire de Beaucaire, Association pour la recherche archéologique en Ianguedoc oriental, cahier $\mathrm{n}^{\circ} 6$, Caveirac.

Delattre G., Ribot H., Theveny J.-M.

1994 : Exploitation de la base informatisée de l'Ouest varois (recherche de sites par modélisation), in : Favory F., Fiches J.-L. (dir.), Les campagnes de la France méditerranéenne dans l'Antiquité et le haut Moyen Âge: études microrégionales, Documents d'archéologie française, 42, Paris, éd. de la Maison des sciences de l'homme, p. 295-310.
Deniaux E.

1993 : Clientèles et pouvoir à l'époque de Cicéron, Rome, coll. de l'École française de Rome, 182, 638 p.

Desbat A.

1998 : L'arrêt des importations de Dressel 1 en Gaule, in: Actes du congrès international de la Société française d'étude de la céramique antique en Gaule, Istres, 21-24 mai 1998, Marseille, p. 31-36.

Desbat A., Genin M.

1996 : Les ateliers précoces et leurs productions, in: Desbat A., Genin M., Lasfargucs J. (éds), Les productions des ateliers de potiers antiques de Lyon, $1^{\text {re }}$ partie : les ateliers précoces, Gallia, 53, p. 1-249.

Desbat A., Genin M., LaRoche C., THIRION P.

1989 : La chronologie des premières trames urbaines à Lyon, in: Goudineau C. (éd.), Aux origines de Lyon, Documents d'archéologie en Rhône-Alpes, 2, série lyonnaise 1, p. 95-126.

\section{DODINET M.}

1985 : Carte archéologique et cadastres romains: l'exemple du nord Biterrois, thèse de Doctorat de $3^{\mathrm{e}}$ cycle, univ. de Besançon, 274 p.

Domergue C.

1965 : Les Planii et leur activité industrielle en Espagne sous la République, Mélanges de la Casa de Velasquez.

1994 : L'État romain et le commerce des métaux à la fin de la République et sous le Haut-Empire, in: Économie antique, les échanges dans l'Antiquité: le rôle de l'État, Actes des entretiens d'archéologie et d'histoire de Saint-Bertrand-de-Comminges, 1994, Saint-Bertrand-de-Comminges, Musée archéologique départemental, p. 99-113.

DOMERgue C. (ÉD.)

1993 : Un centre sidérurgique romain de la Monlagne Noire. Le domaine des Forges (Les Martys, Aude), suppl. 27 à la 
Revue archéologique de Narbonnaise, $477 \mathrm{p}$.

\section{DOMERGUE C. ET AL.}

1997 : Les moulins rotatifs dans les mines et les centres métallurgiques antiques, in: Garcia D., Meeks D. (éds), Techniques el économie antiques et médiévales: le lemps de l'innovation, Actes du colloque d'Aix-en-Provence, mai 1996, Paris, éd. Errance, p. 48-61.

Dubois C.

1992 : Nescus, La Bastide-de-Sérou, Lercoul. Mines, métallurgie et forêts dans les Pyrénées ariégeoises de l'Antiquité au Moyen Âge, in: Vidal M. (dir.), Bilan scientifique de la région Midi-Pyrénées 1992, Service régional de l'archéologie/ministère de la Culture, p. 36-37.

EBel. C.

1976 : Transalpine Gaul, the emergence of a Roman province, Leyde.

FAVORY F.

1997 : Retour critique sur les centuriations du Languedoc oriental, leur existence et leur datation, in: Chouquer G. (dir.), Les formes $d u$ paysage -3- L'analyse des systèmes spatiaux, Paris, éd. Errance, p. 96-126.

FAVORY F., Fiches J.-L. (DIR.)

1994 : Les campagnes de la France méditerranéenne dans l'Antiquité et le haut Moyen Âge : études microrégionales, Documents d'archéologie française, 42, Paris, éd. de la Maison des sciences de l'homme, $339 \mathrm{p}$.

Favory F., Fiches J.-L., RAYNAud C.

1998 : La dynamique de l'habitat galloromain dans la basse vallée du Rhône, in : Collectif Archéomedes, Des oppida aux métropoles. Archéologues et géographes en vallée $d u$ Rhône, Paris, éd. Anthropos, p. 73-116.

Favory F., Girardot J.J., Raynaud C., ROGER K.

1994 : L'habitat gallo-romain autour de l'étang de l'Or (Hérault). Hiérarchie, dynamique et réseaux $d u \mathrm{II}^{e} \mathrm{~s}$. av. au
$\mathrm{V}^{\mathrm{e}}$ s. ap. J.-C., Mélanges Pierre Iévêque, 8 , p. $123-215$.

Favory F., Mathian H., Raynaud C., SANDers Lena L. aVec la collab. DE. GiRADOT J.J.

1998 : Sélection géographique, déterminisme et hasard, in: Collectif Archéomedes, Des oppida aux métropoles. Archéologues et géographes en vallée du Rhône, Paris, éd. Anthropos, p. 151-248.

Favory F., Raynaud C., Roger K.

1996 : La romanisation des campagnes autour de l'étang de l'Or (Hérault), hiérarchie, dynamique et réseaux de l'habitat du $\mathrm{II}^{\mathrm{e}}$ s. av. J.-C. au I ${ }^{\mathrm{er}}$ s. apr. J.-C., in: De la ferme indigène à la villa romaine, Actes du $2^{\text {e }}$ colloque de l'association AGER, Amiens, 23-25 sept. 1993, n spécial de la Revue archéologique de Picardie, 11, p. 305-308.

Feugère M., Passelac M., Pellecuer C., GARMY P. (ÉDS)

1998 : Signes de la romanisation, chronique I, Revue archéologique de Narbonnaise, 31, p. 299-353.

FEugère M., RouQuetTE D.

1985 : Le site antique et médiéval de Saint-Pierre-de-Pabiran à Montagnac (Hérault), Études sur l'Hérault, 1, n. s. 1985 (3), p. 3-10.

FICHES J.-L.

1989 : Tombes et monuments lapidaires dans l'espace rural arécomique $\left(\mathrm{III}^{\mathrm{e}}-\mathrm{I}^{\mathrm{er}}\right.$ s. av.), Mélanges Pierre Lévêque, 2, p. 207-237.

1993a : Les élites nîmoises et les campagnes au Haut-Empire : caractérisation, place et signification de leurs sépultures, in: Monde des morts, monde des vivants en Gaule rurale, Actes du colloque archea/ager, Orléans, 7-9 fév. 1992, $6^{\mathrm{c}}$ suppl. à la Revue archéologique du Centre de la France, p. 325-332.

1993b : Critères de datation et chronologie des limitations romaines en Narbonnaise, Reoue archéologique de Narbonnaise, 26, p. 99-104.

1995 : Tracés directeurs de la Nìmes antique et de ses campagnes. Essai de bibliographie critique, texte introductif de la journée d'étude du GDR 954 du CNRS, Nîmes, 27 fév. 1995, 41 p. dactylogr., inédit.

Fiches J.-L AVEC LA COlLAB. DE AURoux A., Py M., Sanchez C., RouX J.-C.

1994 : Les céramiques d'époque romaine $\left(\mathrm{I}^{\mathrm{er}} \mathrm{s}\right.$. av. n. è.-II ${ }^{\mathrm{e}}$ s. de n. è.), in : Exploration de la ville portuaire de Lattes, Lattara, 7, Lattes, p. 333-372.

FICHES J.-L. (DIR.)

1995 : Habitats de l'Âge du Fer et structures agraires d'époque romaine aux Escaravatiers, Puget-sur-Argens, Var, Gallia, 52, p. 205-262.

GATEAU F.

1996 : L'étang de Berre, Carte archéologique de la Gaule, 13/1, Paris, Fondation Maison des sciences de l'homme, 380 p.

GAYRAUD M.

1981 : Narbonne antique des origines à la fin $d u$ III $s$., suppl. 8 à la Revue archéologique de Narbonnaise, Paris, 594 p.

GenTy P.-Y., FeUgère M.

1995 : Aramon (Gard). La nécropole du $I^{\text {er }}$ siècle avant notre ère, Documents d'archéologie méridionale, 18, p. 143-195.

GrRY J., FEDIÈre G.

1978 : Les cantons de Béziers, répertoire et carte archéologique de l'Hérault, Bulletin de la société archéologique de Béziers, $5^{\mathrm{e}}$ série, XIV, p. 51-93.

1979 : Les cantons de Béziers, répertoire et carte archéologique de l'Hérault, Bulletin de la société archéologique de Béziers, $5^{\mathrm{e}}$ série, XV, p. 47-85.

Goudineau C.

1976 : Le statut de Nîmes et des Volques arécomiques, Revue archéologique de Narbonnaise, IX, p. 105-114.

1978 : La Gaule Transalpine, in: Nicolet C. (dir.), Rome et la conquête du monde méditerranéen -2- La genèse d'un empire, Paris, Presses universitaires de France.

1996 : La Gaule avant César, in: 
Reddé M. (dir.), L'armée romaine en Gaule, Paris, éd. Errance, p. 9-34.

GOURDIOLE R., LANDES C.

1998 : Passions métalliques sur les Monts d'Orb, archéologie et histoire des Hauts Cantons, Bulletin de la société archéologique et historique des Hauts Cantons de l'Hérault, 21, p. 33-50.

2000 : Une société minière italienne en pays rutène, in: Actes du $\mathrm{XXI}^{e}$ colloque international de l'Association française pour l'étude de l'âge du Fer, ConquesMontrozier, 8-11 mai 1997, Monographies d'archéologie méditerranéenne, 6 , p. 61-64.

Gourdiole R., Landes C., Marco M., SALVAIRE M.

1998 : Le site gallo-romain de Bournac (Ceilhes), archéologie et histoire des Hauts Cantons, Bulletin de la société archéologique et historique des Hauts Cantons de l'Hérault, 21, p. 19-32.

GROS P.

1992 : Rome ou Marseille ? Le problème de l'hellénisation de la Gaule Transalpine aux deux derniers siècles de la République, in: Bats M., Bertucchi G., Congès G., Treziny H. (éds), Marseille grecque et la Gaule, Actes du colloque international d'histoire et d'archéologie et du $V^{e}$ congrès archéologique de Gaule méridionale, Marseille, 18-23 nov. 1990, Études massaliètes, 3, p. 369-382.

Guil.baun J.-E., Landes C.

1977 : Les travaux miniers gallo-romains des Barrencs (commune de FournesCabardès, Aude), Bulletin de la société d'études scientifiques de l'Aude, LXXVI, p. 75-81.

\section{HERMON E.}

1993 : Rome et la Gaule Transalpine avant César, $125-59$ av. J.-C., Naples, Jovene editore, $363 \mathrm{p}$.

1994 : Conquête et occupation du sol : structures romaines d'exploitation et communautés rurales transalpines, in: Doukellis N.-P., Mendoni L.-G. (éds), Actes du colloque international de
Corfou, 14-16 mai 1992, Paris, Annales littéraires de l'univ. de Besançon, p. 293-297.

1995 : Pouvoir et revenus en Transalpine au I ${ }^{\text {er }}$ s. av. J.-C. Un aspect du rapport centre-périphérie, Revue des études anciennes, 97, 3-4, p. 565-574.

\section{JORDA M., MOCCI F.}

1997 : Sites protohistoriques et galloromains du massif Sainte-Victoire, in : La dynamique des paysages protohistoriques, antiques, médiévaux et modernes, Actes des $\mathrm{XVII}^{\mathrm{e}}$ rencontres internationales d'archéologie et d'histoire d'Antibes, Sophia Antipolis, 19-21 oct. 1996, Juan-les-Pins, éd. APDCA, p. $211-230$.

KOTARBA J.

1995 : Premières données sur l'occupation humaine du versant nord des Albères durant l'époque romaine et l'Antiquité tardive, in: Cultures $i$ medi de la prehistoria a l'edat mitjana, 20 anys d'arqueologia pirinenca; homenatge al professor Jean Guilaine, Actes du $\mathrm{X}^{\mathrm{e}}$ colloque international d'archéologie de Puigcerdà, 10-12 nov. 1994, Puigcerdà, Institut d'estudis cesetans, p. 549-554.

1996 : Canet-en-Roussillon, Puig del Baja (Pyrénées-Orientales), in: Pellecuer C. (dir.), Formes de l'habitat rural en Gaule Narbonnaise, t. 3, Juanles-Pins, éd. APDCA.

\section{LABROUSSE M.}

1968 : Toulouse antique, des origines à l'établissement des Wisigoths, Paris, 644 p.

LejEUNE M.

1985 : Textes gallo-grecs, in: Duval P.-M. (dir.), Recueil des Inscriptions Gauloises (R.I.G.), I, suppl. XLV à Gallia, Paris, éd. du CNRS, $459 \mathrm{p}$.

Lemaître S., Desbat A., Maza G.

1998 : Les amphores du site du "sanctuaire de Cybèle " à Lyon. Étude préliminaire, in: Actes du congrès international de la Société française d'étude de la céramique antique en Gaule, Istres, 21-24 mai 1998, Marseille, p. 49-60.
Le Roux P.

1982 : L'armée romaine et l'organisation des provinces ibériques, d'Auguste à l'invasion de 409, Paris, éd. du Centre P. Paris, 494 p.

Lugand M., Pellecuer C. aVec la collab. DF. BOU M.-H.

1994 : La région de Mèze et la villa des Prés-Bas à Loupian (Hérault) : contribution à l'étude du littoral languedocien, in: Favory F., Fiches J.-L. (dir.), Les campagnes de la France méditerranéenne dans l'Antiquité et le haut Moyen Âge: études microrégionales, Documents d'archéologie française, 42, Paris, Maison des sciences de l'homme, p. 246-278.

MAUNÉ S.

1993 : À propos du septième kardo du cadastre Béziers B: le site de Balsède III à Pézenas (Hérault), Études sur l'Hérault, n. s. 9, p. 1-4.

1995 : L'occupation du sol en Biterrois nord-oriental à la période précoloniale, 118 av./36 av. J.-C., in: Cité et territoire, Actes du colloque européen de Béziers, 14-16 oct. 1994, Paris, Annales littéraires de l'univ. de Besançon, p. 195-206.

1996 : Le cadastre précolonial dit Béziers B et ses rapports avec les oppida préromains de la moyenne vallée de l'Hérault, in: Archéologie des parcellaires -2- Les formes du paysage, Actes du colloque ager, Orléans 28-30 mars 1996, Paris, éd. Errance, p. 128-141.

1998a: Les campagnes de la cité de Béziers dans l'Antiquité (partie nord-orientale), If s. av.VI s. ap. J.-C., Archéologie et histoire romaine 1, Montagnac, éd. M. Mergoil, 532 p.

$1998 \mathrm{~b}$ : Romanisation et occupation du sol en Gaule Transalpine (II $-\mathrm{I}^{\mathrm{er}} \mathbf{s}$. av. J.-C.), in: Feugère M., Passelac M., Pellecuer C., Garmy P. (éds), Signes de la romanisation, chronique I, Revue archéologique de Narbonnaise, 31, p. 301-306.

À paraître : L'habitat rural dispersé des $\mathrm{II}^{\mathrm{e}}$ et $\mathrm{I}^{\mathrm{cr}}$ s. av. J.-C. en Languedoc occidental et Roussillon, in: Actes $d u$ XXII colloque international pour l'étude de l'âge du Fer, Girona, 21-24 mai 1998. 
Mauné S., Chazelles C.-A. DE

1998 : Dynamique du peuplement et occupation du sol sur le territoire de Montlaurès (Narbonne, Aude), in: Cité et territoire, Actes du $2^{\mathrm{e}}$ colloque européen de Béziers, 24-26 oct. 1997, Paris, Presses universitaires franccomtoises, p. 187-208.

Mauné S., Sanchez C.

1999 : Une production de céramique à vernis noir dans la région de Béziers (Hérault, $\mathrm{II}^{\mathrm{e}} \mathrm{I}^{\mathrm{I} r}$ s. av. J.-C.), Revue archéologique de Narbonnaise, 32, p. 97-117.

MAZA G.

1998 : Recherche méthodologique sur les amphores gréco-italiques et Dressel 1 découverte à Lyon, $\mathrm{II}^{\mathrm{e}}-\mathrm{I}^{\mathrm{er}} \mathrm{s}$. av. J.-C., in: Actes du congrès international de la Sociélé fransaise d'étude de la céramique antique en Gaule, Istres, 21-24 mai 1998, Marseille, p. 11-29.

\section{MEFFRE J.-C.}

1994 : Espace rural autour de Vaison-laRomaine (Vaucluse) : habitats et morphologie agraire à l'époque galloromaine, in: Favory F., Fiches J.-L. (dir.), Les campagnes de la France méditerranéenne dans l'Antiquité et le haut Mojen Âge: études microrégionales, Documents d'archéologie française, 42, Paris, éd. de la Maison des sciences de l'homme, p. 117-133.

\section{MOATTI C.}

1992 : Étude sur l'occupation des terres publiques à la fin de la République romaine, Cahiers du Centre G. Glotz, III, p. 57-73.

1993 : Archives et partage de la terre dans le monde romain (II' siècle avant-IFr siècle après J.-C.), Rome, collection de l'École française de Rome, 173, 174 p.

\section{NicOlet C.}

1967 (rééd. 1990) : Les Cracques. Crise agraire et révolution à Rome, Paris, éd. Gallimard, coll. Archives.

\section{ODIOT T.}

1994 : Habitats, sols et cadastres dans le Tricastin, in: Favory F., Fiches J.-L. (dir.), Les campagnes de la France méditerranéenne dans l'Antiquité et le haut Moyen Âge: études microrégionales, Documents d'archéologie française, 42, Paris, éd. de la Maison des sciences de l'homme, p. 73-107.

OREJAS A., SASTRE I.

1999 : Fiscalité et organisation du territoire dans le nord-ouest de la péninsule Ibérique : civitas, tribut et ager mensura comprehensus, Dialogues d'histoire ancienne, 25/1, p. 159-188.

Passelac M.

1983 : I'occupation des sols en I auragais à l'âge du Fer et pendant la période gallo-romaine : acquis, problèmes et méthodes, in: Actes du LIV congrès de la Fédération historique du Languedoc méditerranéen et du Roussillon et XXXVI congrès de la Fédération des Sociétés académiques et savantes $d u$ Languedoc, Pyrénées, Gascogne, Castelnaudary, 1983, p. 29-63.

1994 : Les fermes de l'âge du Fer, in: Aude des origines, Guilaine J., Sacchi D., Vaquer J. (dir.), Catalogue d'exposition, Carcassonne, p. 103109 .

1998 : Installations pour le travail du fer dans le vicus Eburomagus (Bram, Aude), in: Feugère M., Serneels V. (dir.), Recherches sur l'économie du fer en Méditerranée nord-occidentale, Monographie Instrumentum 4, Montagnac, éd. M. Mergoil, p. 129-141.

Pauc B., Pauc P.

1998 : Quelques sites de réduction du mincrai dc fcr dans les Corbières (Aude), in: Feugère M., Serneels V. (dir.), Recherches sur l'économie du fer en Méditerranée nord-occidentale, Monographie Instrumentum 4, Montagnac, éd. M. Mergoil, p. 116-128.

Pelletier J.-P., Poguet M.

1993 : Des prospections à la fouille: recherches à Eyguières (Bouches-duRhône), Revue archéologique de Narbonnaise, 26, p. 181-246.

1994 : Eyguières, Saint-Pierre 1, in: Pellecuer C. (dir.), Formes de l'habitat rural en Gaule Narbonnaise, t. 2, Juanles-Pins, éd. APDCA.

\section{Poux M.}

1999 : Puits funéraire d'époque gauloise à Paris (Sénat). Une tombe d'auxiliaire républicain dans le sous-sol de Lutèce, Protohistoire européenne, 4, Montagnac, éd. M. Mergoil, 171 p.

Py M.

1990 : Culture, économie et société protohistoriques dans la région nîmoise, RomeParis, collection de l'École française de Rome, 131, 2 vol.

RANCOUle G.

1970 : Ateliers de potiers et céramique indigène au I ${ }^{\mathrm{er}}$ siècle avant J.-C., Revue archéologique de Narbonnaise, III, p. $33-70$.

1980 : La Lagaste, agglomération gauloise du bassin de l'Aude, Atacina, 10 , Carcassonne, 172 p.

1985 : Observations sur la diffusion des importations italiques dans l'Aude aux II $^{\mathrm{e}}$ et $\mathrm{I}^{\mathrm{er}}$ siècles avant J.-C., Revue archéologique de Narbonnaise, 18 , p. 263-275.

1987 : Exemples d'installations protohistoriques isolées en Minervois, Bulletin de la société d'études scientifiques de l'Aude, LXXXVII, p. 15-20.

1992 : Habitat rural des $\mathrm{II}^{\mathrm{e}}$ et $\mathrm{I}^{\mathrm{er}}$ siècles en Minervois oriental et Narbonnais, Bulletin de la société d'études scientifiques de l'Aude, XCII, p. 71-79.

1994 : Les exploitations minières antiques, in: Guilaine J., Sacchi D., Vaquer J. (dir.), Aude des origines, Catalogue d'exposition, Carcassonne, p. 113-116.

\section{RaNCoule G., Schwaller M.}

1994 : Apports ou influences continentales en Languedoc occidental. Recensement, chronologie et réflexions, in: L'âge du Fer en Europe sud-occidentale, Actes du XVIc colloque de l'Association française pour l'étude de l'âge du Fer, Agen, 28-31 mai 1992, Aquitania, 12, p. 223-235.

RAYNAUd C.

1998 : De la prospection à la fouille et retour... Us et abus de la prospection 
méthodique : une expérience languedocienne, Homo Faber, 2.1, p. 7-15.

Rico C.

1997 : Pyrénées romaines. Essai sur un pays de frontière (III siècle av. J.-C.-IV siècle apr. J.-C.), Madrid, Bibliothèque de la Casa de Velazquez, 14, $417 \mathrm{p}$.

Roman D.

1990 : Marseille et la fides de Rome, Revue archéologique de Narbonnaise, 23, p. 213-222.

\section{ROTH CONGÈs A.}

1993 : Les mausolées du sud-est de la Gaule, in: Monde des morts, monde des vivants en Gaule rurale, Actes du colloque archea/ager, Orléans, 7-9 fév. 1992, 6 $6^{\mathrm{c}}$ suppl. à la Revue archéologique du Centre de la France, p. 389-396.

SAUvage L.

1996 : La ville arécomique, in: Fiches J.-L., Veyrac A. (dir.), Nîmes, Carte archéologique de la Gaule, 30/1, Paris, Fondation Maison des sciences de l'homme, p. 146-152.

SÉjALON P.

1998 : Un atelier de potiers gaulois des années $150 / 50$ av. n. è. à Bouriège
(Aude), Revue archéologique de Narbonnaise, 31, p. 1-11.

\section{SOLIER Y.}

1992 : L'occupation des Corbières à l'Âge du Fer. Habitats et mobiliers, Documents d'archéologie méridionale, 15 , p. 327-390.

\section{SORICELli G.}

1995 : La Gallia Transalpina tra la conquista e l'età cesariana, Como, 139 p.

\section{SOYER J.}

1980, Note sur les centuriations romaines dans la plaine du Roussillon, in: Barruol G. (dir.), Ruscino, I, suppl. 7 à la Revue archéologique de Narbonnaise, p. 337-339.

\section{TCHERNIA A.}

1986 : Le vin de l'Italie romaine, essai d'histoire économique d'après les amphores, Rome, Bibliothèques des Écoles françaises d'Athènes et de Rome, 261, 410 p.

\section{TRÉMENT F.}

1996 : Études micro régionales et paléodémographie. L'apport de la recherche autour de Saint-Blaise, in: Gateau F. (dir.), L'étang de Berre, Carte archéologique de la Gaule, 13/1, Paris, Fondation Maison des sciences de l'homme, p. 98-113.

VERDIN F.

1996 : Occupation du sol et territoires à l'âge du Fer: l'exemple de la basse vallée de l'Arc, in: Gateau F. (dir.), L'étang de Berre, Carte archéologique de la Gaule, 13/1, Paris, Fondation Maison des sciences de l'homme, p. 115-120.

1999 : Occupation du sol et pression démographique indigène autour de Marseille au second âge du Fer, in: Bellancourt-Valdher M., Corvisier J.-N. (dir.), La démographie historique antique, Cahiers scientifiques de l'université d'Artois, 11/1999, Arras, p. 51-68.

Vildal. L., Esperou J.-L., Schneider L., Besombes J.P.

1995 : Entre Peyne et Libron, le nord du Biterrois au I ${ }^{\text {er }}$ s. av. J.-C. : apports et limites de l'exploitation des images de surface pour une étude d'archéologie spatiale, in: Cité et territoire, Actes du colloque curopćcn dc Bćzicrs, 14-16 oct. 1994, Paris, Annales littéraires de l'université de Besançon, p. 127-132. 